\title{
Bridging the Gap between Genes and Language Deficits in Schizophrenia: An Oscillopathic Approach
}

\author{
Elliot Murphy ${ }^{1 *}$ and Antonio Benítez-Burraco ${ }^{2}$ \\ ${ }^{1}$ Division of Psychology and Language Sciences, University College London, London, UK, ${ }^{2}$ Department of Philology, \\ University of Huelva, Huelva, Spain
}

Schizophrenia is characterized by marked language deficits, but it is not clear how these deficits arise from the alteration of genes related to the disease. The goal of this paper is to aid the bridging of the gap between genes and schizophrenia and, ultimately, give support to the view that the abnormal presentation of language in this condition is heavily rooted in the evolutionary processes that brought about modern language. To that end we will focus on how the schizophrenic brain processes language and, particularly, on its distinctive oscillatory profile during language processing. Additionally, we will show that candidate genes for schizophrenia are overrepresented among the set of genes that are believed to be important for the evolution of the human faculty of language. These genes crucially include (and are related to) genes involved in brain rhythmicity. We will claim that this translational effort and the links we uncover may help develop an understanding of language evolution, along with the etiology of schizophrenia, its clinical/linguistic profile, and its high prevalence among modern populations.

\section{OPEN ACCESS}

Edited by:

Anne Keitel,

University of Glasgow, UK

Reviewed by:

Carrie E. Bearden,

University of California, USA

Peter Uhlhaas,

University of Glasgow, UK

*Correspondence:

Elliot Murphy

elliotmurphy91@gmail.com

Received: 16 January 2016 Accepted: 08 August 2016

Published: 23 August 2016

Citation:

Murphy $E$ and Benítez-Burraco A (2016) Bridging the Gap between Genes and Language Deficits in Schizophrenia: An Oscillopathic

Approach.

Front. Hum. Neurosci. 10:422. doi: 10.3389/fnhum.2016.00422
Keywords: neural oscillations, schizophrenia, dynome, genome, oscillopathy, language evolution

\section{INTRODUCTION}

Schizophrenia is a pervasive neurodevelopmental disorder entailing several (and severe) social and cognitive deficits (van Os and Kapur, 2009). Usually, people with schizophrenia exhibit language problems at all levels, from phonology to pragmatics, which coalesce into problems for speech perception (auditory verbal hallucinations), abnormal speech production (formal thought disorder), and production of abnormal linguistic content (delusions, commonly understood to be distinct from thought disorders), which are the hallmarks of the disease in the domain of language (Stephane et al., 2007, 2014; Bakhshi and Chance, 2015). Importantly, although schizophrenia is commonly defined as a disturbance of thought or selfhood, some authors claim that most of its distinctive symptoms may arise from language dysfunction; in particular, from failures in language-mediated forms of meaning (Hinzen and Rosselló, 2015).

There is ample evidence that schizophrenia is caused by a complex interaction between genetic, epigenetic, and environmental factors. To date, schizophrenia has been related to mutations, copy number variation, or changes in the expression pattern of an extensive number of genes (see O’Tuathaigh et al., 2012; Flint and Munafò, 2014; McCarthy et al., 2014; Schizophrenia Working Group of the Psychiatric Genomics Consortium, 2014 for recent reviews). Many of them point to specific regulatory and signaling pathways (like dopaminergic, glutamatergic, GABAergic, and cholinergic pathways, the neuregulin signaling pathway, and the Akt/GSK-3 pathway) and to specific neural mechanisms (like those involving dendritic spines and synaptic terminals, 
synapses, gray matter development, and neural plasticity, Buonanno, 2010; Karam et al., 2010; Bennett, 2011; Schizophrenia Working Group of the Psychiatric Genomics Consortium, 2014; Hall et al., 2015). However, the gap between genes, brain abnormalities, and cognitive dysfunction in schizophrenia still remains open, particularly regarding its distinctive linguistic profile.

The goal of this Perspective article is to suggest new ways of bridging the gap between genes and schizophrenia. Cognitive disorders are increasingly being conceived as oscillopathies, or pathological variations of the normal profile of brain rhythmicity (Buzsáki and Watson, 2012; Buzsáki et al., 2013). Current understanding suggests that schizophrenia is characterized by asynchronous neural oscillations, and particularly, by an inhibitory interneuron dysfunction (Moran and Hong, 2011; Pittman-Polletta et al., 2015). Importantly, brain rhythms are heritable components of brain function (Linkenkaer-Hansen et al., 2007), also in pathological conditions (see Hall et al., 2011 for schizophrenia). At the same time, there seems to be a robust link between language disorders and language evolution: recently evolved cognitive abilities are preferably disturbed in disorders because of the reduced resilence of the neural networks (see Benítez-Burraco, 2016 for discussion). The human pattern of brain activity can be conceived of as a slight variation of the patterns observed in other primates (Buzsáki et al., 2013). Accordingly, our species-specific ability to acquire and use languages (aka language-readiness) plausibly resulted from the emergence of a new pattern of cortical inhibition and of longdistance connections across the brain (see Boeckx and BenítezBurraco, 2014a for details), both of which are aspects that are targeted in schizophrenia (Morice and McNicol, 1985; Horn et al., 2012; Jiang et al., 2015). If we are on the right track, we expect that examining language deficits in schizophrenia from this oscillopathic and evolutionary perspective will help us understand its distinctive neurocognitive profile, but also its origins and its prevalence among modern populations.

\section{FROM LANGUAGE DEFICITS TO THE BRAIN IN SCHIZOPHRENIA}

Schizophrenics have been known to have disordered speech (McKenna and Oh, 2005), but the most severe linguistic changes occur at the internal, conceptual level, where studies frequently examine patients who experience thoughts being "inserted" into them from outside sources or "broadcast" out of their minds and into other people's (Crow, 1980; Frith, 1992). Patients also sometimes hear their thoughts "echoed," or spoken aloud, and are also known to experience third-person and second-person auditory hallucinations, with an external voice either discussing them or commenting on their actions (Ramsden, 2013, pp. 234-265). Frith and Allen's (1988) review observed "a failure to structure discourse at higher levels." Abnormalities can also be detected with syntax, however, and this is where we will focus most of our attention. Schizophrenic patients exhibit fewer relative clauses (as their discourse difficulties would predict), shorter utterances, and less clausal embedding (Fraser et al., 1986;
Thomas et al., 1987). Importantly, this relative lack of clausal embedding implies that patients do not engage in thoughts about mental states or Theory of Mind (Morice and Ingram, 1982; Morice and McNicol, 1986).

In contrast to normal left-lateralization of activity in frontotemporal regions during language processing, a wide range of schizophrenic patients exhibit bilateral and right-lateralized activity (Weiss et al., 2005; Diederen et al., 2010). Angrilli et al. (2009) have relatedly proposed that, judging by evoked potentials, certain features of schizophrenia appear to be (partly) a failure of phonological left hemispheric dominance, since the above deficit in lateralization is specific to phonological processing, being absent in semantic and word recognition tasks.

\section{FROM BRAIN RHYTHMICITY TO LANGUAGE DEFICITS IN SCHIZOPHRENIA}

Although schizophrenia was for a time deemed "the graveyard of neuropathology" (Plum, 1972) due to its unusually subtle neurophysiological markers, we believe that research in neuronal dynamics (particularly over the past half-decade) has the potential to carve a clearer image of the abnormally-developing brain. Oscillations play a central role in selectively enhancing neural assembly interconnectivity and information processing through the provision of spatio-temporal windows of enhanced or reduced patterns of excitability (Jensen et al., 2014; Weisz et al., 2014), and are consequently strong candidates for the origin of certain cognitive faculties.

If the translational approach taken in Murphy (2015a, 2016) toward the brain dynamics of language is accurate, and if Hinzen and Rosselló (2015) are correct in claiming that linguistic disorganization in schizophrenia "plays a more central role in the pathogenesis of this disease than commonly supposed," then it is appropriate to inform our understanding of schizophrenia by focusing on the central role of brain rhythms in linguistic computation. If schizophrenia represents a breakdown in normal linguistic cognition, then we would expect to see disruptions in the model of brain dynamics of language processing outlined in Murphy (2015a) when examining the recent, burgeoning literature concerning the oscillatory profile of schizophrenics.

To briefly summarize previous work, it was claimed in Murphy $(2015 a, b)$ that set-formation amounts to the $\alpha$ rhythm embedding cross-cortical $\gamma$ rhythms, with $\alpha$ reflecting longrange cortical interactions (Nunez et al., 2001) and thalamocortical loop activity (Nunez and Srinivasan, 2006). The syntactic operation of "Transfer" (which "chunks" constructed objects into short-term memory) was claimed to amount to the embedding of these $\gamma$ rhythms inside the $\theta$ band, generated in the hippocampus. It was also claimed that labeling (maintaining an item in memory before coupling it with another, yielding an independent syntactic identity) amounts to the slowing down of $\gamma$ to $\beta$ before $\beta-\alpha$ coupling, likely involving a basal ganglia-thalamic-cortical loop. These suggestions are in line with Mai et al.'s (2016) finding of $\gamma$-related modulations during semantic and syntactic processing (our claims should also not be conflated with the well-known phonological oscillatory investigations of Giraud and Poeppel 
(2012). We will adopt these assumptions here when interpreting the rhythmic literature on schizophrenia.

Since schizophrenia, like other cognitive impairments, appears not to be the result of a locally delimited neural deficit but rather emerges from distributed impairments, neural oscillations, and their role in flexible brain connectivity have recently become the target of research. Investigating the frequency and brain location of the neural oscillations involved in lexical processing in schizophrenia, Xu et al. (2013) conducted an MEG study in which patients discriminated correct from incorrect visually presented stimuli. This lexical decision task revealed that the patients, relative to healthy controls, showed abnormal oscillatory activity during periods of lexical encoding and postencoding, particularly in the occipital and left frontal-temporal areas (see also Sun et al., 2014). Since a broad range of rhythms were implicated, we will avoid speculation about the specific operations impaired and instead suggest that the results imply familiar problems with semantic memory. However, the results did reveal reduced temporal lobe $\alpha$ and left frontal lobe $\beta$ activity during lexical processing, suggesting difficulties in assigning lexical classes (labels) to items and successful categorization (findings corroborating the cartographic profile presented above, which included reduced activation during complex sentence processing at left superior frontal cortex). These results corroborate the more general findings of reduced $\alpha$ and $\beta$ in schizophrenia by Moran and Hong (2011) and Uhlhaas et al. (2008). A level of thalamocortical dysrhythmia was also detected by Schulman et al.'s (2011). MEG study; a discovery which bears on the claim that thalamocortical axons also likely play a role in language externalization (Boeckx and Benítez-Burraco, 2014b). These suggested problems with the mechanisms responsible for phrase structure building also gain support from Ghorashi and Spencer's (2015) findings that attentional load increases $\beta$ phase-locking factor at frontal, parietal and occipital sites in healthy controls during a visual oddball task but not in schizophrenic patients (although this varied across individuals of different abilities), with the latter group having difficulty attending to and maintaining relevant objects in memory (perhaps as a result of their semantic memory deficits). $\beta$-generating circuits may well be responsible, then, for the types of computations attributed to them in Murphy (2015a).

An earlier MEG sentence presentation task by Xu et al. (2012) also found reduced $\alpha$ and $\beta$ in left temporal-parietal sites, along with reduced $\delta$ at left parietal-occipital and right temporal sites, and reduced $\theta$ at occipital and right frontal lobe sites, suggesting problems with phrase structure chunking; that is, problems with word movement and phrasal embedding, as attested above (see Ferrarelli et al., 2012). Schizophrenic patients also displayed reduced $\delta$ synchrony at left frontal lobe sites after sentence presentation, suggesting semantic processing dysfunctions. These findings are consistent with Hirayasu et al.'s (1998). MRI study of schizophrenic and bipolar individuals, which reported relatively reduced gray matter volumes in the left superior temporal gyrus for schizophrenics. Their results also give some support to the present hypothesis about chunking difficulties in schizophrenia, since they also reported reduced hippocampal volumes. Altogether, these studies are in agreement the findings of Hoffman et al. (1999), who suggested that the core schizophrenic deficit is not centered on attentionalperceptual cognitive processes, but rather verbal working memory (and, hence, difficulties with syntactic computation, given the "chunking" nature of linguistic phrase structure building; see Narita, 2014), mediated by oscillations generated in the hippocampus and left temporal regions (Murphy, 2015a). Başar-Eroğlu et al. (2011) also documented reduced anterior $\alpha$ in response to simple auditory input, suggesting less efficient processing power.

Power and synchrony reductions in evoked $\gamma$ have also been documented in chronic, first-episode and early-onset schizophrenia (Williams and Boksa, 2010). Given the role of this band in feature binding and object representation (Uhlhaas et al., 2008) and its functional significance in the present model (Murphy, 2015a, 2016), this suggests that schizophrenics have difficulties generating the correct category of semantic objects to employ in successful phrase structure building, as the behavioral results of lexical decision and related tasks appear to verify (likely explaining the features of delusions and formal thought disorder reviewed above). More recent studies appear to support this perspective. The amplitude of EEG $\gamma$ was measured during phonological, semantic, and visuo-perceptual tasks by Spironelli and Angrilli (2015). Schizophrenic patients, relative to normal controls, exhibited a significantly weaker hemispheric asymmetry across all tasks and reduced frontal $\gamma$. Ferrarelli et al. (2008) also found a decreased $\gamma$ response in schizophrenic patients after TMS stimulation to the frontal cortex, suggesting an impaired ability to efficiently generate this rhythm. This is of particular significance given that $\gamma$ amplitude has been shown to scale with the number of items held in working memory (Roux et al., 2012), and the limited phrase structure building and syntactic embedding capacities of schizophrenic patients would follow naturally from these results.

Recall also that the model of linguistic computation adopted here invokes a number of cross-frequency coupling operations. It is of interest, then, that schizophrenic patients showed higher $\gamma$ $\alpha$ cross-frequency coupling in Popov and Popova's (2015) study of general cognitive performance, despite this co-varying with poorer attention and working memory capacities. The reason for this may be that the increased phase-amplitude-locking likely results in smaller "gamma pockets" of working memory items (as Korotkova et al., 2010 argue on independent grounds) and hence low total $\gamma$ power. In this instance, the size and order of working memory sequences outputted by the conceptual systems is not optimally compatible with the oscillopathic profile, leading to greater rhythmic excitability, and yet inhibited linguistic functionality. Global rhythmicity is consequently disrupted due to unusually strong fronto-parietal interconnectivity. We believe that this represents a genuine neural mechanism of an "interface" between syntactically generated conceptual representations and external (memory) systems; a highly significant finding if corroborated by further experimental studies.

Corroborating Angrilli et al.'s (2009) above hypothesis about schizophrenia being a failure of left-hemispheric phonological dominance, an MEG study of the oscillatory differences between bipolar disorder and schizophrenia revealed that schizophrenic 
patients showed delayed phase-locking in response to speech sounds in the left hemisphere, relative to bipolar individuals and normal controls (Oribe et al., 2010). This lack of lefthemispheric dominance may trigger confusion about internal and external voices and bring about a number of delusions, with language's normal computational functioning being derailed. The left hypofrontality documented by Spironelli et al. (2011), with schizophrenic patients showing greater $\delta$ amplitudes over language-relevant sites (that is, greater functional inhibition), similarly point to a general functional deficit at the core memory sites of linguistic representations. It is also significant that the role attributed to $\theta$ in the present dynomic model gains support from the finding that this rhythm has greater amplitude in left superior temporal cortex during auditory hallucinations in schizophrenia (Ishii et al., 2000), as opposed to steady $\theta$ during resting state, with patients being seemingly incapable of regulating chunking operations. Given the identification of such dysrhythmias in schizophrenia, repetitive TMS (rTMS) could be used as a therapeutic intervention to modulate the oscillations responsible for the abnormal linguistic profile documented above, as has been done to improve performance on visual tasks (Farzan et al., 2012; Barr et al., 2013). The oscillopathic profile constructed here is presented in Table 1.

\section{SCHIZOPHRENIA-RELATED GENES AND SOME EVOLUTIONARY CONCERNS}

As noted in the introduction, the number of genes related to schizophrenia has been growing over recent years. Interestingly, some of them are involved in the maintenance of the adequate balance between neuronal excitation and inhibition and/or have been related to language dysfunction. Likewise, as we also noted above and will discuss in detail below, a robust link exists between evolution and abnormal development and, in particular, between language evolution and schizophrenia. In this section we focus on candidate genes for schizophrenia that are involved in brain rhythmicity and that have been related to language impairment or to the dysfunction of basic cognitive abilities involved in language processing, but also on genes important for language evolution that play a role in brain rhythmicity and that are candidates for schizophrenia. The genes we highlight seem to us robust candidates for language deficits in this condition.

\section{Schizophrenia-Candidates and Brain Rhythmicity}

Among the genes related to schizophrenia that play a role in brain oscillations and that have been associated to language dysfunction one finds ZNF804A. This gene encodes a zinc finger binding protein important for cortical functioning and neural connectivity, involved in growth cone function and neurite elongation (Hinna et al., 2015). GWAs analyses have identified a SNP tagging an intronic region of the gene (Gurung and Prata, 2015) which have been found to impact on white matter microstructure (Mallas et al., 2016). Schizophrenia risk polymorphisms of ZNF804A have been also related to differences in performance in the domain of phonology, such as in reading and spelling tasks (Becker et al., 2012), but also in the domain of semantics, specifically in task evaluating category fluency (Nicodemus et al., 2014). ZNF804A modulates hippocampal $\gamma$ oscillations and, ultimately, the co-ordination of distributed networks belonging to the hippocampus and the prefrontal cortex (Cousijn et al., 2015), which are aspects known to be impaired in schizophrenia, as noted above (Uhlhaas et al., 2008; Godsil et al., 2013). Likewise, both NRG1 and its receptor ERBB4, which have been posited as promising candidates for schizophrenia as resulting from next-generation sequencing analyses (Agim et al., 2013; Hatzimanolis et al., 2013), enhance synchronized oscillations of neurons in the prefrontal cortex, known to be reduced in schizophrenia, via inhibitory synapses (Fisahn et al., 2009; Hou et al., 2014). Specifically NRG1 increases the synchrony of pyramidal neurons via presynaptic interneurons and the synchrony between pairs of interneurons through their mutually-inhibitory synapses (Hou et al., 2014). Risk polymorphisms of NRG1 are associated with increased IQs as well as memory and learning performance, along with language in subjects with bipolar disorder (Rolstad et al., 2015). Moreover, risk alleles for the gene correlate with reduced left superior temporal gyrus volumes (a robust imaging finding in schizophrenia, Tosato et al., 2012), a region related to language abilities (Aeby et al., 2013). Another gene of interest is PDGFR, which encodes the $\beta$ subunit of the platelet-derived growth factor (PDGF) receptor, known to be involved in the development of the central nervous system. Pdgfr- $\beta$ knocked-out mice show reduced auditory phase-locked $\gamma$ oscillations, which correlates with anatomical (e.g., reduced density of GABAergic neurons in the amygdala, hippocampus, and medial prefrontal cortex), physiological (alterations of prepulse inhibition) and behavioral (reduced social behavior, impaired spatial memory and problems with conditioning) hallmarks of schizophrenia (Nguyen et al., 2011; Nakamura et al., 2015). Additional evidence of the involvement of this gene in schizophrenia comes from risk polymorphisms analyses (Kim et al., 2008). Interestingly, PDGFRA has been found to act downstream of FOXP2, the renowned "language gene," to promote neuronal differentiation (Chiu et al., 2014, more on FOXP2 below).

Other genes of interest encode ion channels. Genome-wide analyses (GWAs) have identified the schizophrenia risk gene CACNA1I as one of the genes that may contribute to sleep spindle deficits (Manoach et al., 2015). Sleep spindles are a type of brain rhythm that recurs during non-rapid eye movement sleep and that constrains aspects of the thalamocortical crosstalk, impacting on sensory transmission, cortical plasticity, memory consolidation, and learning (Manoach et al., 2015). CACNA1I encodes a calcium channel and is abundantly expressed in the spindle generator of the thalamus. Likewise CACNA1C encodes the alpha $1 \mathrm{C}(\alpha 1 \mathrm{C})$ subunit of the Cav1.2 voltagedependent L-type calcium channel, a calcium channel involved in the generation of $\beta$ to $\gamma$ waves during wakefulness and rapid eye movement (REM) sleep, and ultimately in sleep modulation; all of which are aspects known to be altered in schizophrenics (Kumar et al., 2015). Intriguingly, CACNA1C is related to semantic (but not lexical) verbal fluency in healthy individuals; conversely, risk alleles of this gene correlate with 
TABLE 1 | Summary of the present cognome-dynome model of linguistic computation and the observed differences in schizophrenia, where "cognomen" refers to the operations available to the human nervous system (Poeppel, 2012) and "dynome" refers to brain dynamics (Kopell et al., 2014); ISTG denotes left superior temporal gyrus, AVH denotes auditory verbal hallucination.

\begin{tabular}{|c|c|c|}
\hline Frequency band & Role in the present model of language computation & Observed and predicted differences in schizophrenia \\
\hline Delta $(\sim 0.5-4 \mathrm{~Hz})$ & Involved in phrasal processing and possibly labeling. & $\begin{array}{l}\text { Reduced at left parietal-occipital sites during sentence } \\
\text { processing; predicted to be disrupted in processing phrasal } \\
\text { embedding and relative clauses. }\end{array}$ \\
\hline Theta $(\sim 4-10 \mathrm{~Hz})$ & $\begin{array}{l}\text { Hippocampal source; embeds } \gamma \text { to generate cyclic transfer of } \\
\text { syntactic objects; involved more generally in memory retrieval. }\end{array}$ & $\begin{array}{l}\text { Reduced at occipital and frontal lobe sites during sentence } \\
\text { processing; increased at ISTG during AVHs; predicted to be } \\
\text { reduced in deictic and definite NPs. }\end{array}$ \\
\hline Alpha $(\sim 8-12 \mathrm{~Hz})$ & $\begin{array}{l}\text { Synchronizes distant cortical regions; embeds } \gamma \text { generated } \\
\text { cross-cortically to yield inter-modular set-formation; involved in } \\
\text { lexical decision making. }\end{array}$ & $\begin{array}{l}\text { Reduced at left temporal lobe during lexical and sentence } \\
\text { processing; predicted to be disrupted during certain } \\
\text { lexicalisations. }\end{array}$ \\
\hline Beta $(\sim 10-30 \mathrm{~Hz})$ & $\begin{array}{l}\text { When } \gamma \text { is slowed to } \beta \text { and coupled with } \alpha \text { via a basal } \\
\text { ganglia-thalamic-cortical loop, syntactic objects are labeled; } \\
\text { holds objects in memory. }\end{array}$ & $\begin{array}{l}\text { Reduced at left frontal lobe during lexical processing; predicted } \\
\text { to be disrupted in the maintenance of syntactic objects in } \\
\text { embedded clauses. }\end{array}$ \\
\hline Gamma ( 30-100 Hz) & $\begin{array}{l}\text { Generates syntactic objects before } \beta \text { holds them in memory; } \\
\text { central role in a number of linguistic operations; involved in } \\
\text { lexical processing. }\end{array}$ & $\begin{array}{l}\text { Reduced at frontal sites during semantic tasks; higher } \\
\text { cross-frequency coupling with occipital } \alpha \text {; predicted to be } \\
\text { disrupted in language-related memory tasks. }\end{array}$ \\
\hline
\end{tabular}

lower performance scores, and thus with non-fluent verbal performance of schizophrenics (Krug et al., 2010). Two proteins associated with ion channels are also worth considering, namely DPP10 and CNTNAP2. DPP10 is a membrane protein that binds specific $\mathrm{K}^{+}$channels and modifies their expression and biophysical properties (Djurovic et al., 2010). Also CNTNAP2 is associated with $\mathrm{K}^{+}$voltage-gated channels, particularly, in the axon initial segment of pyramidal cells in the temporal cortex, that are mostly innervated by GABAergic interneurons (Inda et al., 2006). Several studies have correlated CNTNAP2 with schizophrenia, including CNV and SNPs studies (Friedman et al., 2008; Ji et al., 2013). The gene is also a candidate for several types of language disorders, including child apraxia of speech (Worthey et al., 2013), dyslexia (Peter et al., 2011), SLI (Newbury et al., 2011), language delay, and language impairment (Petrin et al., 2010; Sehested et al., 2010). CNTNAP2 additionally affects language development in the normal population (Whalley et al., 2011; Whitehouse et al., 2011; Kos et al., 2012), apparently because of its effects on brain connectivity and cerebral morphology (Scott-Van Zeeland et al., 2010; Tan et al., 2010; Dennis et al., 2011) and dendritic arborization and spine development (Anderson et al., 2012). CNTNAP2 is also a target of FOXP2 (Vernes et al., 2008).

Several genes encoding neurotransmitter receptors have been also related to both abnormal brain oscillation patterns and language deficits in schizophrenia. HTR1A encodes the receptor $1 \mathrm{~A}$ of serotonin and modulates hippocampal $\gamma$ oscillations, seemingly impacting on behavioral and cognitive functions, such as learning and memory linked to serotonin function (Johnston et al., 2014). Several studies involving common polymorphisms of this gene highlight HTR1A as a promising candidate for schizophrenia risk, treatment response to the disease, and cognitive dysfunction in this condition (Gu et al., 2013; Lin et al., 2015; Takekita et al., 2015). Similarly, receptors of NMDA, particularly those containing the subunit NR2A, encoded by GRIN2A, are known to be reduced in fast-firing interneurons in schizophrenics, which plays a critical role in $\gamma$ oscillation formation; a blockade of NR2A-containing receptors gives rise to strong increases in $\gamma$ power and a reduction in low-frequency $\gamma$ modulation (Kocsis, 2012). More generally, functional (GT)n polymorphisms in the promoter of the gene have been associated with the disease (Iwayama-Shigeno et al., 2005; Tang et al., 2006; Liu et al., 2015), and genome-wide association analyses has identified GRIN2A as a risk factor for schizophrenia (Lencz and Malhotra, 2015), emerging as a promising candidate because of its expression in the adult neocortex (Ohi et al., 2016). Additionally, mutations in GRIN2A cause epilepsy-aphasia spectrum disorders, including LandauKleffner syndrome and continuous spike and waves during slowwave sleep syndrome (CSWSS), in which speech impairment and language regression are prominent symptoms (Carvill et al., 2013; Lesca et al., 2013). The gene has been related as well to rolandic epilepsies, the most frequent epilepsies in childhood, in which cognitive, speech, language, and reading problems are commonly observed (Dimassi et al., 2014). Speech problems linked to GRIN2A mutations include imprecise articulation, impaired pitch and prosody, and hypernasality, as well as poor performance on maximum vowel duration and repetition of monosyllables and trisyllables, resulting in lifelong dysarthria and dyspraxia (Turner et al., 2015). Finally, cannabinoid-1receptor, encoded by CNR1, modulates $\theta$ and $\gamma$ oscillations in several areas of the brain, including the hippocampus, impacting on sensory gating function in the limbic circuitry (Hajós et al., 2008). CNR1-positive GABA-ergic interneurons have been also involved in several aspects of behavior, including response to auditory cues (Brown et al., 2014). Translational convergent functional genomics studies have highlighted CNR1 as an important gene for schizophrenia onset (Ayalew et al., 2012). Several risk polymorphisms of the gene have been related to the disease, and specifically, to brain changes and metabolic disturbances in schizophrenics (Yu et al., 2013; Suárez-Pinilla et al., 2015). Interestingly, CNR1 has also been linked to cases 
of complete absence of expressive speech (Poot et al., 2009). CNR1 is functionally linked to the last gene we wish to highlight, namely, DISC1 (Xie et al., 2015). DISC1 encodes a protein involved in neurite outgrowth, cortical development and callosal formation (Brandon and Sawa, 2011; Osbun et al., 2011). DISC1 is a historical candidate for schizophrenia (but also to other cognitive disorders like ASD), although its status as a candidate is controversial, provided that most GWAs and CNV analyses have been unable to independently implicate it in the disease (see Farrell et al., 2015 for discussion; see Ayalew et al., 2012 for a promising result). Nonetheless, in hippocampal area CA1 of a transgenic mouse that expresses a truncated version of Disc1 mimicking the schizophrenic genotype, $\theta$ burst-induced longterm potentiation (and ultimately, long-term synaptic plasticity) has been found altered (Booth et al., 2014). The ability of DISC1 to regulate excitatory-inhibitory synapse formation by cortical interneurons depends on its inhibitory effect on NRG1-induced ERBB4 activation and signaling, ultimately effecting the spiking interneuron-pyramidal neuron circuit (Seshadri et al., 2015). DISC1 is also a target of FOXP2 (Walker et al., 2012).

\section{Schizophrenia-Candidates and Language Evolution}

As pointed out above, there exists a robust link between evolution and abnormal development. Because, as noted in the introduction, brain rhythms are heritable components of brain function, and because patterns of brain rhythmicity are species-specific and disorder-specific, we hypothesized that new candidates for language dysfunction in schizophrenia under our oscillopathic view may emerge from the examination of candidate genes for the evolution of language-readiness in our species. As we also pointed out in the introduction, our distinctive ability for acquiring and using language has been hypothesized to have resulted from the emergence of new patterns of cortical rhythmic coupling that habilitated the neuronal workspace needed for transcending the boundaries of core knowledge systems and being able to form cross-modular concepts (known to be affected in schizophrenia); in turn, these changes may have resulted from the brain changes linked to the globularization of the anatomically-modern human (AMH) skull (see Boeckx and Benítez-Burraco, 2014a for details). In a series of related papers, we have put forth a list of tentative candidates for globularization and language-readiness (Boeckx and BenítezBurraco, 2014a,b; Benítez-Burraco and Boeckx, 2015; see Table 2). As discussed there, core candidates for globularization and language readiness fulfill the following criteria: they show (or are functionally related to genes showing) differences with extinct hominin species, particularly, with Neanderthals/Denisovans, which affect their regulatory regions, their coding regions, and/or their methylation patterns; they play some role in brain growth, regionalization, and/or neural interconnection; they have been associated (or are functionally related to genes associated) to conditions in which language, or cognitive abilities important for language, are impaired; and they are candidates (or are functionally related to candidates) for craniosynostosis or some other conditions affecting skull development. Our list of candidates encompasses genes involved in bone development, brain development (specifically of GABAergic neurons), and more generally, brain-skull cross-talk, like RUNX2, some DLX genes (including $D L X 1, D L X 2, D L X 5$, and $D L X 6$ ), and some $B M P$ genes (like $B M P 2$ and $B M P 7$ ). It also includes genes that regulate subcortical-cortical axon pathfinding and that are involved in the externalization of language (such as FOXP2, ROBO1, and the genes encoding the SLITs factors). Finally, it also comprises genes connecting the former two interactomes, including AUTS2 and some of its partners. We have found ample evidence, in silico and in the available literature, supporting the biological reliability of these interactomes. Moreover, we have collected some empirical evidence suggesting that many of the genes we regard important for language evolution are dysregulated in clinical conditions involving skull, brain, and cognitive anomalies. Accordingly, differential expression of several of our candidates (DLX5, ROBO1, SLIT2, NCAM1, TGFB2, DCN, RUNX2, and SFRP2) was found in vivo in the sutures of people with non-syndromic craniosynostosis, which are prematurely ossified, and also in vitro in cells induced toward osteogenic differentiation (Lattanzi et al., 2016).

Interestingly, we have found that candidates for schizophrenia are overrepresented among the genes highlighted by BenítezBurraco and Boeckx (Table 2). Accordingly, nearly 5\% of the human genes are expected to be related to the disease [assuming that the human genome contains about 20,000 protein-coding genes and that about 1000 of them have been associated to schizophrenia, according to the Schizophrenia Gene repository (http://www.szgene.org/)], In turn, around $30 \%$ of candidates for language readiness are also candidates for schizophrenia (42 out of 153 in Table 2). Because the involvement of these genes in language development and evolution, this overlapping may account for the observed deficits in schizophrenia regarding language abilities. These genes are discussed in detail in the Supplementary Materials to this paper. Moreover, several of these common candidates for languagereadiness and schizophrenia also play a role in brain rhythmicity, including AKT1, APOE, DLX5, DLX6, EGR1, FMR1, GAD1, MAPK14, MECP2, and SIRT1 (Table 2). These genes attracted our attention as promising new candidates for the oscillopathic nature of language deficits in schizophrenia. Finally, some of the candidates for the schizophrenia dynome interact with some of the genes encompassing these interactomes important for our language-readiness (Figure S2). In our opinion, all these findings reinforce the view that language impairment in schizophrenia results from (and can be confidently construed in terms of) abnormal patterns of brain connectivity and dynamics.

This overrepresentation of candidates for schizophrenia among the genes involved in language evolution is an intriguing finding. It has been hypothesized that schizophrenia candidate genes were involved in the evolution of the human brain and that the processes they contributed to improving are identical to those impaired in schizophrenics. For example, the human prefrontal cortex, which is responsible for many human-specific cognitive abilities, is differently organized in humans compared to great apes as a result of a recent reorganization of the frontal 
TABLE 2 | Genes discussed in Section Schizophrenia-related genes and some evolutionary concerns.

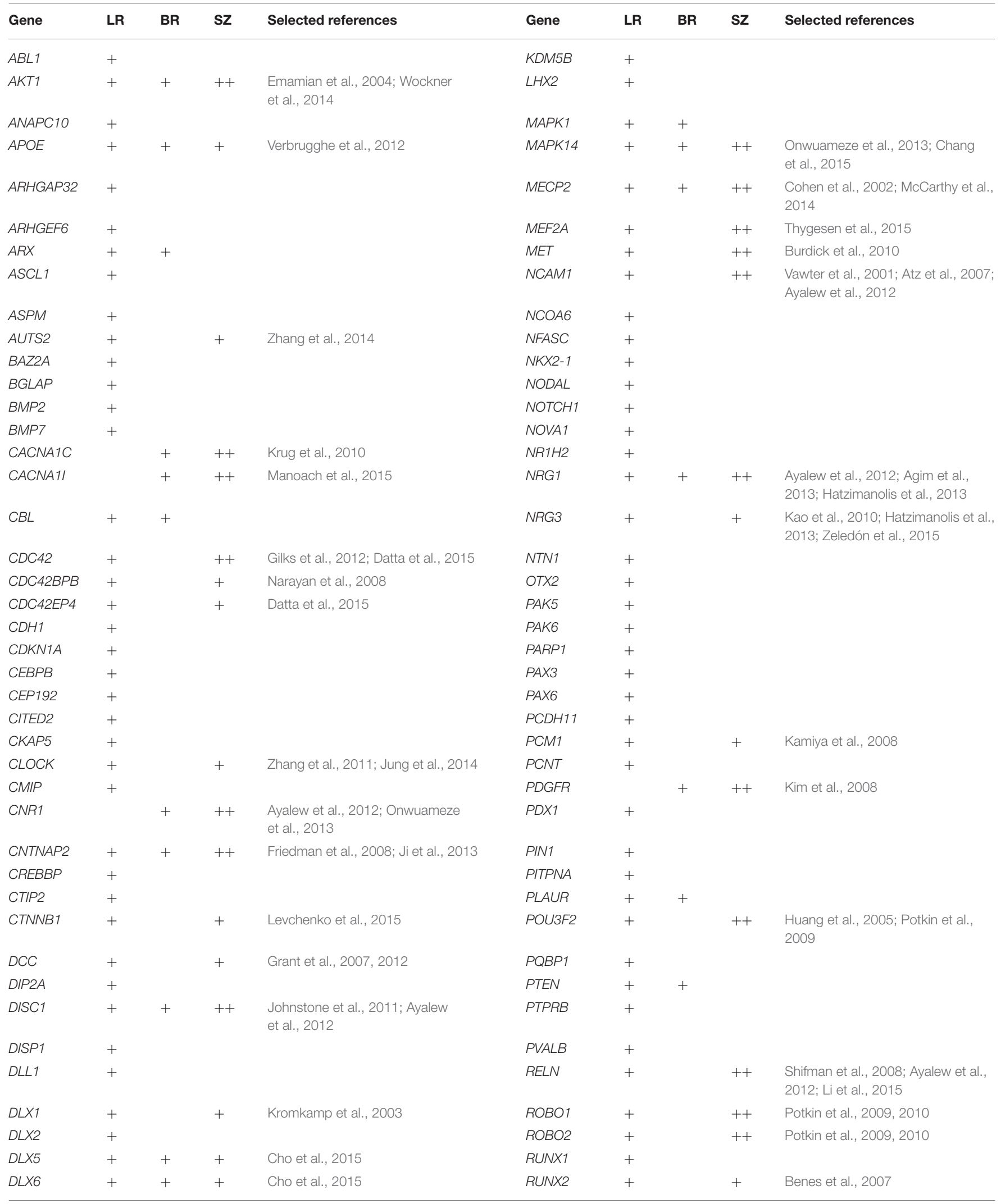


TABLE 2 | Continued

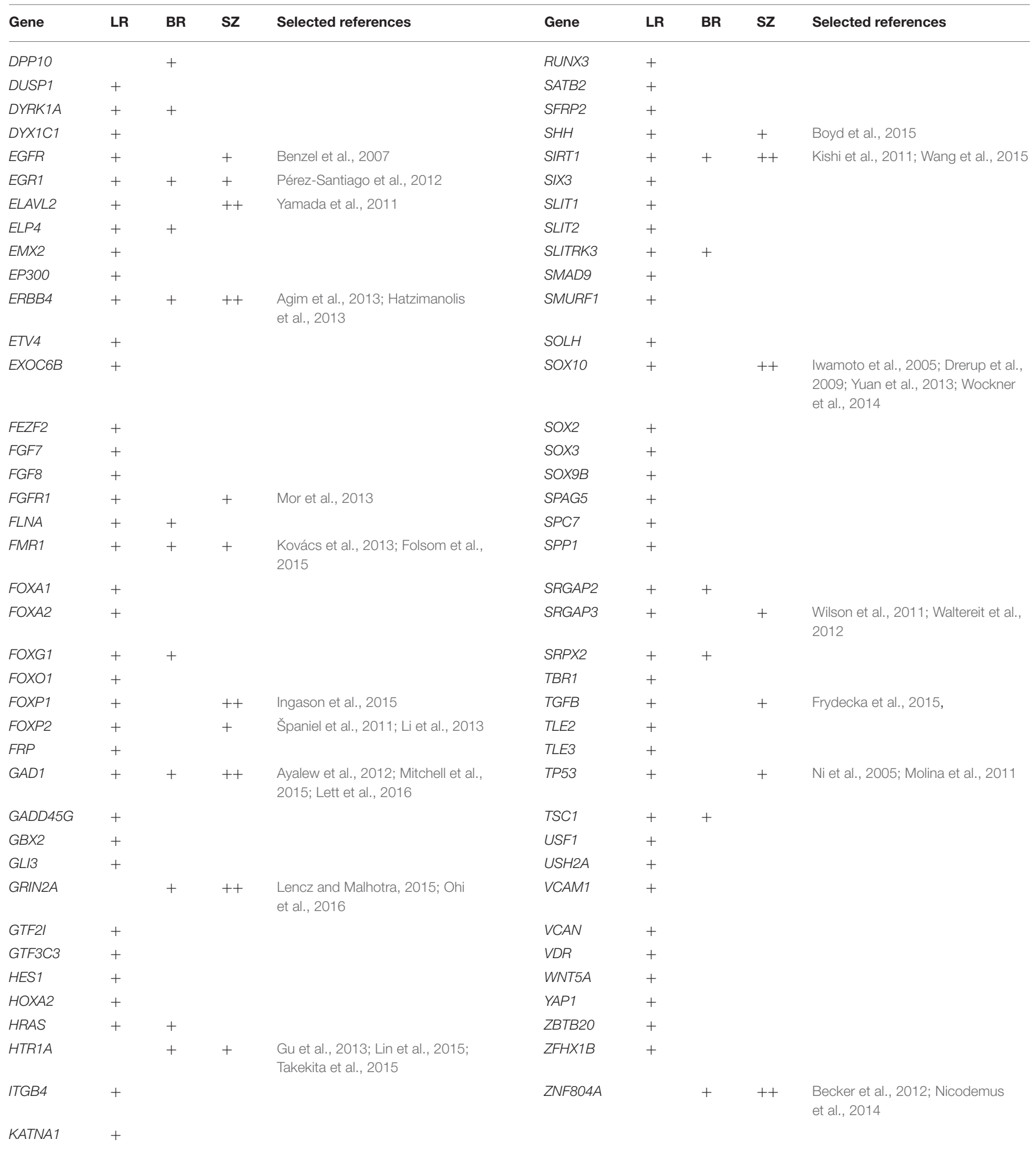

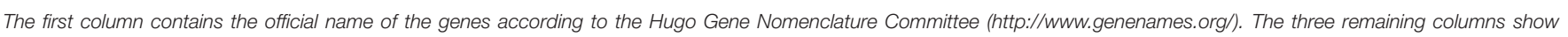

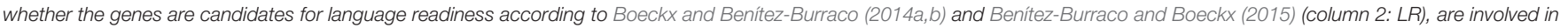

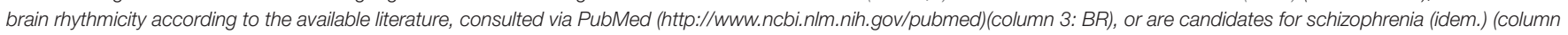

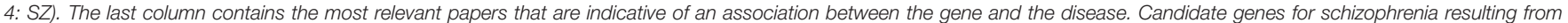

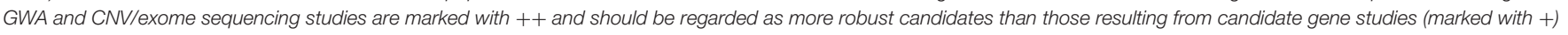
(for further details, see the Supplementary Files). 
cortical circuitry; at the same time, these circuits are impaired in schizophrenia and other psychiatric and neurological conditions (Teffer and Semendeferi, 2012). Nonetheless, when it comes to testing this hypothesis, contradictory results have been obtained. Concerning the protein-coding regions of genes associated to psychiatric disorders Ogawa and Vallender (2014) did not find evidence of differential selection in humans compared to nonhuman primates, although elevated $\mathrm{dN} / \mathrm{dS}$ was observed in primates and other large-brained taxa like cetaceans (dN/dS is the average number of nucleotide differences between sequences per non-synonymous site referred to the average number of nucleotide differences between sequences per synonymous site; $\mathrm{dN} / \mathrm{dS}$ values that are significantly higher than 1 are indicative of positive selection). However, recent analyses based on large GWAs of schizophrenia and data of selective sweeps in the human genome compared to Neanderthals suggest that brainrelated genes showing signals of recent positive selection in AMHs are also significantly associated with schizophrenia (Srinivasan et al., 2016), supporting the view that schizophrenia may be a by-product of the changes in the human brain that led to modern cognition. Interestingly, among the loci highlighted by Srinivasan et al. (2016), we have found several genes related to language development, language impairment, and language evolution, which strike us as new promising candidates for language dysfunction in schizophrenia. Among them, we wish highlight: FOXP1, GATAD2B, MEF2C, NRG3, NRXN1, and ZNF804A (see Supplementary Materials for details). We wish also highlight that some of the genes involved in brain rhythmicity (reviewed above) also show differences in the human lineage. DPP10 shows signals of differential expression in the human brain compared to primates and sequences at DPP10 show regulatory motifs absent in archaic hominins and signals of strong selection in modern human populations (Shulha et al., 2012). Likewise, DISC1 interacts with PCNT, mentioned by Green et al. (2010) as being amongst the proteins that show nonsynonymous and non-fixed changes compared to Neanderthals, and a candidate for dyslexia (Poelmans et al., 2011). Finally, the human CNTNAP2 protein bears a fixed change (I345V) compared to the Denisovan variant (Meyer et al., 2012) and it is related in addition to NFASC, a protein involved in postsynaptic development and neurite outgrowth (Kriebel et al., 2012) which also shows a fixed change (T987A) in AMHs compared to Neanderthals/Denisovans (Pääbo, 2014, Table S1).

Some authors have explicitly linked the aetiopathology of schizophrenia and the evolution of language. According to Arbib and Mundhenk (2005) the primate mirror neurons, which fire both when the animal manipulates an object and when it sees another conspecific manipulating it, provided the scaffolding for imitation abilities involved in language acquisition. At the same time, schizophrenics show a spared ability to generate actions, whether manual or verbal, but they lack the ability to attribute the generation of that action to themselves. More drastically, Crow (1997) suggested that schizophrenia is the "price we paid for language." According to him, schizophrenia represents an extreme of variation of hemispheric specialization and a single genetic mechanism (involving both the $\mathrm{X}$ and $\mathrm{Y}$ chromosomes) that was modified during recent human history can account for this variation, because it generates epigenetic diversity related to both the species capacity for language and the predisposition to psychosis (Crow, 2008).

Our findings provide a different causative explanation to the origins and prevalence of schizophrenia, while still supporting the view that the etiopathology of this condition is heavily rooted in the evolution of human cognition. The genes discussed here map onto specific neuronal types (mostly, GABAergic), particular brain areas (several cortical layers, thalamic nuclei), particular physiological processes (the balance between inhibition and excitation), specific developmental processes (inter and interhemispheric axon pathfinding), and particular cognitive abilities (formal thought), all of which are aspects known to be impaired in schizophrenia. At the same time, all of them are involved in language development and processing and many of them have been modified during our recent evolutionary history. Interestingly, schizophrenia associations have been recently proved to be strongly enriched at enhancers that are active in tissues with important immune functions, giving support to the view that immune dysregulation plays a role in schizophrenia (Schizophrenia Working Group of the Psychiatric Genomics Consortium, 2014). Likewise, changes in the brain/immune system crosstalk have been hypothesized to have contributed to the changes in brain connectivity that prompted the emergence of our language-readiness (BenítezBurraco and Uriagereka, 2015).

Accordingly, instead of thinking of schizophrenia as the "price we paid for language," we believe a more accurate claim is that schizophrenia is the price we paid for a globular braincase housing more efficient and widespread recursive oscillatory embeddings. Because the more novel a neural network is in evolutionary terms, the less resilient it is (due to its lack of robust compensatory mechanisms, Toro et al., 2010), schizophrenia is found as a high prevalent condition among modern populations. This view is in line with current approaches to the etiology of complex diseases in humans, according to which high prevalent conditions of a multifactorial nature resulted from the decanalization of the robust primate condition as a consequence of our evolutionary history (involving demographic bottlenecks, specific mutations, and cultural changes that uncovered cryptic variation, see Gibson, 2009 for details).

\section{CONCLUSIONS}

The considerations we have made here may provide a suitable response to Dehaene et al.'s $(2015$, p. 2) observation that linguistic computation requires "a specific recursive neural code, as yet unidentified by electrophysiology, possibly unique to humans, and which may explain the singularity of human language and cognition." Hierarchical rhythmic coupling operations of the kind proposed in Murphy (2015a, 2016) and discussed here may also provide ways of integrating different forms of hierarchical representations, such as phonological, semantic and syntactic information (see Ding et al., 2016). Disruptions to the present dynomic model of linguistic computation may represent a comprehensive, unifying account of language-related 
neurocognitive disorders As we have argued, schizophrenia is of particular interest because it represents a mode of cognition and externalization of thought distinct from, but plainly related to, normally functioning linguistic cognition. Importantly, this deviance seems construable in terms of an alteration of the cognome-dynome cross-talk. A dynomic perspective cuts across the traditional positive-negative symptom division, being implicated both in abnormal active processes and in the absence of normal functions. This view is in line with more general, recent moves in neuroscience to view psychiatric illnesses as oscillatory connectomopathies (Cao et al., 2016; Vinogradov and Herman, 2016). At the same time, the considerations we have presented also reinforce the view that the survey of the evolutionary itinerary followed by our faculty of language should help unravel abnormal cognitive/linguistic development in our species (and vice versa). The high number of candidates for schizophrenia selected in our species ostensibly proves this. We further expect that the present proposal has the potential to provide robust endophenotypes of schizophrenia (in the form of specific brain oscillation patterns and novel gene candidates) and contribute to an improved diagnosis and treatment of the disorder.

\section{REFERENCES}

Aeby, A., De Tiège, X., Creuzil, M., David, P., Balériaux, D., Van Overmeire, B., et al. (2013). Language development at 2 years is correlated to brain microstructure in the left superior temporal gyrus at term equivalent age: a diffusion tensor imaging study. Neuroimage 78, 145-151. doi: 10.1016/j.neuroimage.2013.03.076

Agim, Z. S., Esendal, M., Briollais, L., Uyan, O., Meschian, M., Martinez, L. A., et al. (2013). Discovery, validation and characterization of Erbb4 and $\mathrm{Nrg} 1$ haplotypes using data from three genome-wide association studies of schizophrenia. PLoS ONE 8:e53042. doi: 10.1371/journal.pone.0053042

Anderson, G. R., Galfin, T., Xu, W., Aoto, J., Malenka, R. C., and Südhof, T. C. (2012). Candidate autism gene screen identifies critical role for cell-adhesion molecule CASPR2 in dendritic arborization and spine development. Proc. Natl. Acad. Sci. U.S.A. 109, 18120-18125. doi: 10.1073/pnas.1216398109

Angrilli, A., Spironelli, C., Elbert, T., Crow, T. J., Marano, G., and Stegagnno, L. (2009). Schizophrenia as failure of left hemispheric dominance for the phonological component of language. PLoS ONE 4:e4507. doi: 10.1371/journal.pone. 0004507

Arbib, M. A., and Mundhenk, T. N. (2005). Schizophrenia and the mirror system: an essay. Neuropsychologia 43, 268-280. doi: 10.1016/j.neuropsychologia. 2004.11.013

Atz, M. E., Rollins, B., and Vawter, M. P. (2007). NCAM1 association study of bipolar disorder and schizophrenia: polymorphisms and alternatively spliced isoforms lead to similarities and differences. Psychiatr. Genet. 17, 55-67. doi: 10.1097/YPG.0b013e328012d850

Ayalew, M., Le-Niculescu, H., Levey, D. F., Jain, N., Changala, B., Patel, S. D., et al. (2012). Convergent functional genomics of schizophrenia: from comprehensive understanding to genetic risk prediction. Mol. Psychiatry 17, 887-905. doi: $10.1038 / \mathrm{mp} .2012 .37$

Bakhshi, K., and Chance, S. A. (2015). The neuropathology of schizophrenia: a selective review of past studies and emerging themes in brain structure and cytoarchitecture. Neuroscience 303, 82-102. doi: 10.1016/j.neuroscience.2015. 06.028

Barr, M. S., Farzan, F., Rajji, T. K., Voineskos, A. N., Blumberger, D. M., Arenovich, T., et al. (2013). Can repetitive magnetic stimulation improve cognition in schizophrenia? Pilot data from a randomized controlled trial. Biol. Psychiatry 73, 510-517. doi: 10.1016/j.biopsych.2012.08.020

\section{AUTHOR CONTRIBUTIONS}

EM contributed primarily to Sections From language deficits to the brain in schizophrenia and From brain rhythmicity to language deficits in schizophrenia, $\mathrm{AB}$ contributed primarily to Sections Introduction and Schizophrenia-related genes and some evolutionary concerns. Both authors contributed equally to Section Conclusions.

\section{ACKNOWLEDGMENTS}

Preparation of this work was supported in part by funds from the Spanish Ministry of Economy and Competitiveness (grant numbers FFI-2013-43823-P and FFI2014-61888-EXP to AB) and an Economic and Social Research Council scholarship (number 1474910 to EM).

\section{SUPPLEMENTARY MATERIAL}

The Supplementary Material for this article can be found online at: http://journal.frontiersin.org/article/10.3389/fnhum. 2016.00422

Başar-Eroğlu, C., Mathes, B., Brand, A., and Schmiedt-Fehr, C. (2011). Occipital gamma response to auditory stimulation in patients with schizophrenia. Int. J. Psychophysiol. 79, 3-8. doi: 10.1016/j.ijpsycho.2010. 10.011

Becker, J., Czamara, D., Hoffmann, P., Landerl, K., Blomert, L., Brandeis, D., et al. (2012). Evidence for the involvement of ZNF804A in cognitive processes of relevance to reading and spelling. Transl. Psychiatry 2, e136. doi: 10.1038/tp.2012.62

Benes, F. M., Lim, B., Matzilevich, D., Walsh, J. P., Subburaju, S., and Minns, M. (2007). Regulation of the GABA cell phenotype in hippocampus of schizophrenics and bipolars. Proc. Natl. Acad. Sci. U.S.A. 104, 10164-10169. doi: 10.1073/pnas.0703806104

Benítez-Burraco, A. (2016). "A biolinguistic approach to language disorders: towards a paradigm shift in clinical linguistics," in Advances in Biolinguistics: The Human Language Faculty and Its Biological Basis, eds K. Fujita and C. Boeckx (London: Routledge), 256-272.

Benítez-Burraco, A., and Boeckx, C. (2015). Possible functional links among brainand skull-related genes selected in modern humans. Front. Psychol. 6:794. doi: 10.3389/fpsyg.2015.00794

Benítez-Burraco, A., and Uriagereka, J. (2015). The immune syntax revisited: opening new windows on language evolution. Front. Mol. Neurosci. 8:84. doi: 10.3389/fnmol.2015.00084

Bennett, M. R. (2011). Schizophrenia: susceptibility genes, dendritic-spine pathology and gray matter loss. Prog. Neurobiol. 95, 275-300. doi: 10.1016/j.pneurobio.2011.08.003

Benzel, I., Bansal, A., Browning, B. L., Galwey, N. W., Maycox, P. R., McGinnis, R., et al. (2007). Interactions among genes in the ErbB-Neuregulin signalling network are associated with increased susceptibility to schizophrenia. Behav. Brain Funct. 3:31. doi: 10.1186/1744-9081-3-31

Boeckx, C., and Benítez-Burraco, A. (2014a). The shape of the human languageready brain. Front. Psychol. 5:282. doi: 10.3389/fpsyg.2014.00282

Boeckx, C., and Benítez-Burraco, A. (2014b). Globularity and language-readiness: generating new predictions by expanding the set of genes of interest. Front. Psychol. 5:1324. doi: 10.3389/fpsyg.2014.01324

Booth, C. A., Brown, J. T., and Randall, A. D. (2014). Neurophysiological modification of CA1 pyramidal neurons in a transgenic mouse expressing a truncated form of disrupted-in-schizophrenia 1. Eur. J. Neurosci. 39, 1074-1090. doi: 10.1111/ejn.12549 
Boyd, P. J., Cunliffe, V. T., Roy, S., and Wood, J. D. (2015). Sonic hedgehog functions upstream of disrupted-in-schizophrenia 1 (disc1): implications for mental illness. Biol. Open 4, 1336-1343. doi: 10.1242/bio.012005

Brandon, N. J., and Sawa, A. (2011). Linking neurodevelopmental and synaptic theories of mental illness through DISC1. Nat. Rev. Neurosci. 12, 707-722. doi: $10.1038 / \mathrm{nrn} 3120$

Brown, J. A., Horváth, S., Garbett, K. A., Schmidt, M. J., Everheart, M., Gellért, L., et al. (2014). The role of cannabinoid 1 receptor expressing interneurons in behavior. Neurobiol. Dis. 63, 210-221. doi: 10.1016/j.nbd.2013.11.001

Buonanno, A. (2010). The neuregulin signaling pathway and schizophrenia: from genes to synapses and neural circuits. Brain Res. Bull. 83, 122-131. doi: 10.1016/j.brainresbull.2010.07.012

Burdick, K. E., DeRosse, P., Kane, J. M., Lencz, T., and Malhotra, A. K. (2010). Association of genetic variation in the MET proto-oncogene with schizophrenia and general cognitive ability. Am. J. Psychiatry 167, 436-443. doi: 10.1176/appi.ajp.2009.09050615

Buzsáki, G., Logothetis, N., and Singer, W. (2013). Scaling brain size, keeping timing: evolutionary preservation of brain rhythms. Neuron $80,751-764$. doi: 10.1016/j.neuron.2013.10.002

Buzsáki, G., and Watson, B. O. (2012). Brain rhythms and neural syntax: implications for efficient coding of cognitive content and neuropsychiatric disease. Dialogues Clin. Neurosci. 14, 345-367.

Cao, H., Dixson, L., Meyer-Lindenberg, A., and Tost, H. (2016). Functional connectivity measures as schizophrenia intermediate phenotypes: advances, limitations, and future directions. Curr. Opin. Neurobiol. 36, 7-14. doi: 10.1016/j.conb.2015.07.008

Carvill, G. L., Regan, B. M., Yendle, S. C., O'Roak, B. J., Lozovaya, N., Bruneau, N., et al. (2013). GRIN2A mutations cause epilepsy-aphasia spectrum disorders. Nat. Genet. 45, 1073-1076. doi: 10.1038/ng.2727

Chang, S., Fang, K., Zhang, K., and Wang, J. (2015). Network-based analysis of schizophrenia genome-wide association data to detect the joint functional association signals. PLOS ONE 10:e0133404. doi: 10.1371/journal.pone. 0133404

Chiu, Y. C., Li, M. Y., Liu, Y. H., Ding, J. Y., Yu, J. Y., and Wang, T. W. (2014). Foxp2 regulates neuronal differentiation and neuronal subtype specification. Dev. Neurobiol. 74, 723-738. doi: 10.1002/dneu.22166

Cho, K. K., Hoch, R., Lee, A. T., Patel, T., Rubenstein, J. L., and Sohal, V. S. (2015). Gamma rhythms link prefrontal interneuron dysfunction with cognitive inflexibility in Dlx5/6(+/-) mice. Neuron 85, 1332-1343. doi: 10.1016/j.neuron.2015.02.019

Cohen, D., Lazar, G., Couvert, P., Desportes, V., Lippe, D., Mazet, P., et al. (2002). MECP2 mutation in a boy with language disorder and schizophrenia. Am. J. Psychiatry 159, 148-149. doi: 10.1176/appi.ajp.159.1.148-a

Cousijn, H., Tunbridge, E. M., Rolinski, M., Wallis, G., Colclough, G. L., Woolrich, M. W., et al. (2015). Modulation of hippocampal theta and hippocampalprefrontal cortex function by a schizophrenia risk gene. Hum. Brain Mapp. 36, 2387-2395. doi: 10.1002/hbm.22778

Crow, T. J. (1980). Molecular pathology of schizophrenia: more than one disease process? Br. Med. J. 280, 66-68. doi: 10.1136/bmj.280.6207.66

Crow, T. J. (1997). Is schizophrenia the price that Homo sapiens pays for language? Schizophr. Res. 28, 127-141. doi: 10.1016/S0920-9964(97)00110-2

Crow, T. J. (2008). The 'big bang' theory of the origin of psychosis and the faculty of language. Schizophr. Res. 102, 31-52. doi: 10.1016/j.schres.2008.03.010

Datta, D., Arion, D., Corradi, J. P., and Lewis, D. A. (2015). Altered expression of CDC42 signaling pathway components in cortical layer 3 pyramidal cells in schizophrenia. Biol. Psychiatry 78, 775-785. doi: 10.1016/j.biopsych.2015.03.030

Dehaene, S., Meyniel, F., Wacongne, C., Wang, L., and Pallier, C. (2015). The neural representation of sequences: from transition probabilities to algebraic patterns and linguistic trees. Neuron 88, 2-19. doi: 10.1016/j.neuron.2015.09.019

Dennis, E. L., Jahanshad, N., Rudie, J. D., Brown, J. A., Johnson, K., McMahon, K. L., et al. (2011). Altered structural brain connectivity in healthy carriers of the autism risk gene, CNTNAP2. Brain Connect. 1, 447-459. doi: 10.1089/brain.2011.0064

Diederen, K. M. J., De Weijer, A. D., Daalman, K., Blom, J. D., Neggers, S. F. W., Kahn, R. S., et al. (2010). Decreased language lateralization is characteristic of psychosis, not auditory hallucinations. Brain 133, 3734-3744. doi: 10.1093/brain/awq313
Dimassi, S., Labalme, A., Lesca, G., Rudolf, G., Bruneau, N., Hirsch, E., et al. (2014). A subset of genomic alterations detected in rolandic epilepsies contains candidate or known epilepsy genes including GRIN2A and PRRT2. Epilepsia 55, 370-378. doi: 10.1111/epi.12502

Ding, N., Melloni, L., Zhang, H., Tian, X., and Poeppel, D. (2016). Cortical tracking of hierarchical linguistic structures in connected speech. Nat. Neurosci. 19, 158-164. doi: 10.1038/nn.4186

Djurovic, S., Gustafsson, O., Mattingsdal, M., Athanasiu, L., Bjella, T., Tesli, M., et al. (2010). A genome-wide association study of bipolar disorder in Norwegian individuals, followed by replication in Icelandic sample. J. Affect. Disord. 126, 312-316. doi: 10.1016/j.jad.2010.04.007

Drerup, C. M., Wiora, H. M., Topczewski, J., and Morris, J. A. (2009). Disc1 regulates foxd 3 and sox10 expression, affecting neural crest migration and differentiation. Development 136, 2623-2632. doi: 10.1242/dev.030577

Emamian, E. S., Karayiorgou, M., and Gogos, J. A. (2004). Decreased phosphorylation of NMDA receptor type 1 at serine 897 in brains of patients with schizophrenia. J. Neurosci. 24, 1561-1564. doi: 10.1523/JNEUROSCI. 4650-03.2004

Farrell, M. S., Werge, T., Sklar, P., Owen, M. J., Ophoff, R. A., O’Donovan, M. C., et al. (2015). Evaluating historical candidate genes for schizophrenia. Mol. Psychiatry 20, 555-562. doi: 10.1038/mp.2015.16

Farzan, F., Barr, M. S., Sun, Y., Fitzgerald, P. B., and Daskalakis, Z. J. (2012). Transcranial magnetic stimulation on the modulation of gamma oscillations in schizophrenia. Ann. N.Y. Acad. Sci. 1265, 25-35. doi: 10.1111/j.17496632.2012.06543.x

Ferrarelli, F., Massimini, M., Peterson, M. J., Riedner, B. A., Lazar, M., Murphy, M. J., et al. (2008). Reduced evoked gamma oscillations in the frontal cortex in schizophrenia patients: a TMS/EEG study. Am. J. Psychiatry 165, 996-1005. doi: 10.1176/appi.ajp.2008.07111733

Ferrarelli, F., Sarasso, S., Guller, Y., Riedner, B. A., Peterson, M. J., Bellesi, M., et al. (2012). Reduced natural oscillatory frequency of frontal thalamocortical circuits in schizophrenia. Arch. Gen. Psychiatry 69, 766-774. doi: 10.1001/archgenpsychiatry.2012.147

Fisahn, A., Neddens, J., Yan, L., and Buonanno, A. (2009). Neuregulin-1 modulates hippocampal gamma oscillations: implications for schizophrenia. Cereb. Cortex 19, 612-618. doi: 10.1093/cercor/bhn107

Flint, J., and Munafò, M. R. (2014). Genetics: finding genes for schizophrenia. Curr. Biol. 24, R755-R757. doi: 10.1016/j.cub.2014.07.018

Folsom, T. D., Thuras, P. D., and Fatemi, S. H. (2015). Protein expression of targets of the FMRP regulon is altered in brains of subjects with schizophrenia and mood disorders. Schizophr. Res. 165, 201-211. doi: 10.1016/j.schres.2015.04.012

Fraser, W., King, K., Thomas, P., and Kendall, R. E. (1986). The diagnosis of schizophrenia by language analysis. Br. J. Psychiatry 148, 275-278. doi: 10.1192/bjp.148.3.275

Friedman, J. I., Vrijenhoek, T., Markx, S., Janssen, I. M., van der Vliet, W. A., Faas, B. H., et al. (2008). CNTNAP2 gene dosage variation is associated with schizophrenia and epilepsy. Mol. Psychiatry 13, 261-266. doi: 10.1038/sj.mp. 4002049

Frith, C. D. (1992). The Cognitive Neuropsychology of Schizophrenia. Hove: Lawrence Erlbaum Associates.

Frith, C. D., and Allen, H. A. (1988). "Language disorders in schizophrenia and their implications for neuropsychology," in Schizophrenia: The Major Issues, eds P. Bebbington and P. McGuffin (Oxford: Heinemann), 172-186.

Frydecka, D., Misiak, B., Pawlak-Adamska, E., Karabon, L., Tomkiewicz, A., Sedlaczek, P., et al. (2015). Sex differences in TGFB- $\beta$ signaling with respect to age of onset and cognitive functioning in schizophrenia. Neuropsychiatr. Dis. Treat. 11, 575-584. doi: 10.2147/NDT.S74672

Ghorashi, S., and Spencer, K. M. (2015). Attentional load effects on beta oscillations in healthy and schizophrenic individuals. Front. Psychiatry 6:149. doi: 10.3389/fpsyt.2015.00149

Gibson, G. (2009). Decanalization and the origin of complex disease. Nature Rev. Genet. 10, 134-140. doi: 10.1038/nrg2502

Gilks, W. P., Hill, M., Gill, M., Donohoe, G., Corvin, A. P., and Morris, D. W. (2012). Functional investigation of a schizophrenia GWAS signal at the CDC42 gene. World J. Biol. Psychiatry 13, 550-554. doi: 10.3109/15622975.2012.666359

Giraud, A.-L., and Poeppel, D. (2012). Cortical oscillations and speech processing: emerging computational principles and operations. Nat. Neurosci. 15, 11-517. doi: $10.1038 / \mathrm{nn} .3063$ 
Godsil, B. P., Kiss, J. P., Spedding, M., and Jay, T. M. (2013). The hippocampal-prefrontal pathway: the weak link in psychiatric disorders? Eur. Neuropsychopharmacol. 23, 1165-1181. doi: 10.1016/j.euroneuro.2012.10.018

Grant, A., Fathalli, F., Rouleau, G., Joober, R., and Flores, C. (2012). Association between schizophrenia and genetic variation in DCC: a case-control study. Schizophr. Res. 137, 26-31. doi: 10.1016/j.schres.2012.02.023

Grant, A., Hoops, D., Labelle-Dumais, C., Prévost, M., Rajabi, H., Kolb, B., et al. (2007). Netrin-1 receptor-deficient mice show enhanced mesocortical dopamine transmission and blunted behavioural responses to amphetamine. Eur. J. Neurosci. 26, 3215-3228. doi: 10.1111/j.1460-9568.2007.05888.x

Green, R. E., Krause, J., Briggs, A. W., Maricic, T., Stenzel, U., Kircher, M., et al. (2010). A draft sequence of the Neandertal genome. Science 328, 710-722. doi: $10.1126 /$ science. 1188021

Gu, H., Liu, C., Liu, C., Chen, M., Zhang, Q., Zhai, J., et al. (2013). The combined effects of the 5- HTTLPR and HTR1A rs6295 polymorphisms modulate decision making in schizophrenia patients. Genes Brain Behav. 12, 133-139. doi: 10.1111/j.1601-183X.2012.00866.x

Gurung, R., and Prata, D. P. (2015). What is the impact of genome-wide supported risk variants for schizophrenia and bipolar disorder on brain structure and function? A systematic review. Psychol. Med. 45, 2461-2480. doi: $10.1017 /$ S0033291715000537

Hajós, M., Hoffmann, W. E., and Kocsis, B. (2008). Activation of cannabinoid1 receptors disrupts sensory gating and neuronal oscillation: relevance to schizophrenia. Biol. Psychiatry 63, 1075-1083. doi: 10.1016/j.biopsych.2007. 12.005

Hall, J., Trent, S., Thomas, K. L., O’Donovan, M. C., and Owen, M. J. (2015). Genetic risk for schizophrenia: convergence on synaptic pathways involved in plasticity. Biol. Psychiatry 77, 52-58. doi: 10.1016/j.biopsych.2014.07.011

Hall, M. H., Taylor, G., Sham, P., Schulze, K., Rijsdijk, F., Picchioni, M., et al. (2011). The early auditory gamma-band response is heritable and a putative endophenotype of schizophrenia. Schizophr. Bull. 37, 778-787. doi: $10.1093 / \mathrm{schbul} / \mathrm{sbp} 134$

Hatzimanolis, A., McGrath, J. A., Wang, R., Li, T., Wong, P. C., Nestadt, G., et al. (2013). Multiple variants aggregate in the neuregulin signaling pathway in a subset of schizophrenia patients. Transl. Psychiatry. 3, e264. doi: $10.1038 /$ tp.2013.33

Hinna, K. H., Rich, K., Fex-Svenningsen, Å., and Benedikz, E. (2015). The rat homolog of the schizophrenia susceptibility gene ZNF804A is highly expressed during brain development, particularly in growth cones. PLOS ONE 10:e0132456. doi: 10.1371/journal.pone.0132456

Hinzen, W., and Rosselló, J. (2015). The linguistics of schizophrenia: thought disturbance as language pathology across positive symptoms. Front. Psychol. 6:971. doi: $10.3389 /$ fpsyg.2015.00971

Hirayasu, Y., Shenton, M. E., Salisbury, D. F., Dickey, C. C., Fischer, I. A., Mazzoni, P., et al. (1998). Lower left temporal lobe MRI volumes in patients with firstepisode schizophrenia compared with psychotic patients with first episode affective disorder and normal subjects. Am. J. Psychiatry 155, 1384-1391. doi: 10.1176/ajp.155.10.1384

Hoffman, R. E., Rapaport, J., Mazure, C. M., and Quinlan, D. M. (1999). Selective speech perception alterations in schizophrenic patients reporting hallucinated "voices." Am. J. Psychiatry 156, 393-399.

Horn, H., Jann, K., Federspiel, A., Walther, S., Wiest, R., Müller, T., et al. (2012). Semantic network disconnection in formal thought disorder. Neuropsychobiology 66, 14-23. doi: 10.1159/000337133

Hou, X. J., Ni, K. M., Yang, J. M., and Li, X. M. (2014). Neuregulin 1/ErbB4 enhances synchronized oscillations of prefrontal cortex neurons via inhibitory synapses. Neuroscience. 261, 107-117. doi: 10.1016/j.neuroscience.2013.12.040

Huang, Y. T., Iwamoto, K., Kurosaki, T., Nasu, M., and Ueda, S. (2005). The neuronal POU transcription factor Brn-2 interacts with Jab1, a gene involved in the onset of neurodegenerative diseases. Neurosci. Lett. 382, 175-178. doi: 10.1016/j.neulet.2005.03.008

Inda, M. C., DeFelipe, J., and Muñoz, A. (2006). Voltage-gated ion channels in the axon initial segment of human cortical pyramidal cells and their relationship with chandelier cells. Proc. Natl. Acad. Sci. U.S.A. 103, 2920-2925. doi: 10.1073/pnas.0511197103

Ingason, A., Giegling, I., Hartmann, A. M., Genius, J., Konte, B., Friedl, M., et al. (2015). Expression analysis in a rat psychosis model identifies novel candidate genes validated in a large case-control sample of schizophrenia. Transl. Psychiatry 5, e656. doi: 10.1038/tp.2015.151
Ishii, R., Shinosaki, K., Ikejiri, I., Ukai, S., Yamashita, K., Iwase, M., et al. (2000). Theta rhythm increases in left superior temporal cortex during auditory hallucinations in schizophrenia: a case report. Neuroreport 11, 3283-3287. doi: 10.1097/00001756-200009280-00047

Iwamoto, K., Bundo, M., Yamada, K., Takao, H., Iwayama-Shigeno, Y., Yoshikawa, T., et al. (2005). DNA methylation status of SOX10 correlates with its downregulation and oligodendrocyte dysfunction in schizophrenia. J. Neurosci. 25, 5376-5381. doi: 10.1523/JNEUROSCI.0766-05.2005

Iwayama-Shigeno, Y., Yamada, K., Itokawa, M., Toyota, T., Meerabux, J. M. A., Minabe, Y., et al. (2005). Extended analyses support the association of a functional (GT)n polymorphism in the GRIN2A promoter with Japanese schizophrenia. Neurosci. Lett. 378, 102-105. doi: 10.1016/j.neulet.2004. 12.013

Jensen, O., Gips, B., Bergmann, T. O., and Bonnefond, M. (2014). Temporal coding organized by coupled alpha and gamma oscillations prioritize visual processing. Trends Neurosci. 37, 357-369. doi: 10.1016/j.tins.2014.04.001

Ji, W., Li, T., Pan, Y., Tao, H., Ju, K., Wen, Z., et al. (2013). CNTNAP2 is significantly associated with schizophrenia and major depression in the Han Chinese population. Psychiatry Res. 207, 225-228. doi: 10.1016/j.psychres.2012. 09.024

Jiang, L., Xu, Y., Zhu, X. T., Yang, Z., Li, H. J., and Zuo, X. N. (2015). Localto-remote cortical connectivity in early- and adulthood-onset schizophrenia. Transl. Psychiatry 5, e566. doi: 10.1038/tp.2015.59

Johnston, A., McBain, C. J., and Fisahn, A. (2014). 5-Hydroxytryptamine1A receptor-activation hyperpolarizes pyramidal cells and suppresses hippocampal gamma oscillations via Kir3 channel activation. J. Physiol. 592, 4187-4199. doi: 10.1113/jphysiol.2014.279083

Johnstone, M., Thomson, P. A., Hall, J., McIntosh, A. M., Lawrie, S. M., and Porteous, D. J. (2011). DISC1 in schizophrenia: genetic mouse models and human genomic imaging. Schizophr. Bull. 37, 14-20. doi: $10.1093 / \mathrm{schbul} / \mathrm{sbq} 135$

Jung, J. S., Lee, H. J., Cho, C. H., Kang, S. G., Yoon, H. K., Park, Y. M., et al. (2014). Association between restless legs syndrome and CLOCK and NPAS2 gene polymorphisms in schizophrenia. Chronobiol. Int. 31, 838-844. doi: 10.3109/07420528.2014.914034

Kamiya, A., Tan, P. L., Kubo, K., Engelhard, C., Ishizuka, K., Kubo, A., et al. (2008). Recruitment of PCM1 to the centrosome by the cooperative action of DISC1 and BBS4: a candidate for psychiatric illnesses. Arch. Gen. Psychiatry 65, 996-1006. doi: 10.1001/archpsyc.65.9.996

Kao, W. T., Wang, Y., Kleinman, J. E., Lipska, B. K., Hyde, T. M., Weinberger, D. R., et al. (2010). Common genetic variation in Neuregulin 3 (NRG3) influences risk for schizophrenia and impacts NRG3 expression in human brain. Proc. Natl. Acad. Sci. U.S.A. 107, 15619-15624. doi: 10.1073/pnas.1005410107

Karam, C. S., Ballon, J. S., Bivens, N. M., Freyberg, Z., Girgis, R. R., LizardiOrtiz, J. E., et al. (2010). Signaling pathways in schizophrenia: emerging targets and therapeutic strategies. Trends Pharmacol. Sci. 31, 381-390. doi: 10.1016/j.tips.2010.05.004

Kim, H. J., Kim, M. H., Choe, B. K., Kim, J. W., Park, J. K., Cho, A. R., et al. (2008). Genetic association between $5^{\prime}$-upstream single-nucleotide polymorphisms of PDGFRB and schizophrenia in a Korean population. Schizophr Res. 103, 201-208. doi: 10.1016/j.schres.2008.04.031

Kishi, T., Fukuo, Y., Kitajima, T., Okochi, T., Yamanouchi, Y., Kinoshita, Y., et al. (2011). SIRT1 gene, schizophrenia and bipolar disorder in the Japanese population: an association study. Genes Brain Behav. 10, 257-263. doi: 10.1111/j.1601-183X.2010.00661.x

Kocsis, B. (2012). Differential role of NR2A and NR2B subunits in N-methyl$\mathrm{D}$-aspartate receptor antagonist-induced aberrant cortical gamma oscillations. Biol. Psychiatry 71, 987-995. doi: 10.1016/j.biopsych.2011.10.002

Kopell, N. J., Gritton, H. J., Whittington, M. A., and Kramer, M. A. (2014). Beyond the connectome: the dynome. Neuron 83, 1319-1328. doi: 10.1016/j.neuron.2014.08.016

Korotkova, T., Fuchs, E. C., Ponomarenko, A., von Engelhardt, J., and Monyer, H. (2010). NMDA receptor ablation on parvalbumin-positive interneurons impairs hippocampal synchrony, spatial representations, and working memory. Neuron 68, 557-569. doi: 10.1016/j.neuron.2010.09.017

Kos, M., van den Brink, D., Snijders, T. M., Rijpkema, M., Franke, B., Fernandez, G., et al. (2012). CNTNAP2 and language processing in healthy individuals as measured with ERPs. PLOS ONE 7:e46995. doi: 10.1371/journal.pone. 0046995 
Kovács, T., Kelemen, O., and Kéri, S. (2013). Decreased fragile X mental retardation protein (FMRP) is associated with lower IQ and earlier illness onset in patients with schizophrenia. Psychiatry Res. 210, 690-693. doi: 10.1016/j.psychres.2012.12.022

Kriebel, M., Wuchter, J., Trinks, S., and Volkmer, H. (2012). Neurofascin: a switch between neuronal plasticity and stability. Int. J. Biochem. Cell. Biol. 44, 694-697. doi: 10.1016/j.biocel.2012.01.012

Kromkamp, M., Uylings, H. B., Smidt, M. P., Hellemons, A. J., Burbach, J. P., and Kahn, R. S. (2003). Decreased thalamic expression of the homeobox gene DLX1 in psychosis. Arch. Gen. Psychiatry 60, 869-874. doi: 10.1001/archpsyc. 60.9 .869

Krug, A., Nieratschker, V., Markov, V., Krach, S., Jansen, A., Zerres, K., et al. (2010). Effect of CACNA1C rs1006737 on neural correlates of verbal fluency in healthy individuals. Neuroimage 49, 1831-1836. doi: 10.1016/j.neuroimage.2009.09.028

Kumar, D., Dedic, N., Flachskamm, C., Voulé, S., Deussing, J. M., and Kimura, M. (2015). Cacnalc (Cav1.2) modulates electroencephalographic rhythm and rapid eye movement sleep recovery. Sleep 38, 1371-1380. doi: $10.5665 /$ sleep. 4972

Lattanzi, W., Di Pietro, L., Barba, M., Boeckx, C., Massimi, L., Chieffo, D., et al. (2016). "Differential expression of candidate genes for skull globularization in nonsyndromic craniosinostosis patients: a common molecular network in skull shape evolution, craniofacial dysmorphology and cognitive disabilities?" in The European Human Genetics Conference 2016 (poster presentation) (Barcelona).

Lencz, T., and Malhotra, A. K. (2015). Targeting the schizophrenia genome: a fast track strategy from GWAS to clinic. Mol. Psychiatry 20, 820-826. doi: 10.1038/mp.2015.28

Lesca, G., Rudolf, G., Bruneau, N., Lozovaya, N., Labalme, A., Boutry-Kryza, N., et al. (2013). GRIN2A mutations in acquired epileptic aphasia and related childhood focal epilepsies and encephalopathies with speech and language dysfunction. Nat. Genet. 45, 1061-1066. doi: 10.1038/ng.2726

Lett, T. A., Kennedy, J. L., Radhu, N., Dominguez, L. G., Chakravarty, M. M., Nazeri, A., et al. (2016). Prefrontal white matter structure mediates the influence of GAD1 on working memory. Neuropsychopharmacology 41, 2224-2231. doi: 10.1038/npp.2016.14

Levchenko, A., Davtian, S., Freylichman, O., Zagrivnaya, M., Kostareva, A., and Malashichev, Y. (2015). Beta-catenin in schizophrenia: possibly deleterious novel mutation. Psychiatry Res. 228, 843-848. doi: 10.1016/j.psychres.2015. 05.014

Li, T., Zeng, Z., Zhao, Q., Wang, T., Huang, K., Li, J., et al. (2013). FoxP2 is significantly associated with schizophrenia and major depression in the Chinese Han population. World J. Biol. Psychiatry 14, 146-150. doi: 10.3109/15622975. 2011.615860

Li, W., Guo, X., and Xiao, S. (2015). Evaluating the relationship between reelin gene variants (rs7341475 and rs262355) and schizophrenia: a meta-analysis. Neurosci. Lett. 609, 42-47. doi: 10.1016/j.neulet.2015.10.014

Lin, H., Lei, Y., Zhang, B., Dai, Z., and Lu, X. (2015). Common variants of HTR1A and SLC6A4 confer the increasing risk of Schizophrenia susceptibility: a population-based association and epistasis analysis. Am. J. Med. Genet. B Neuropsychiatr. Genet. 168, 749-755. doi: 10.1002/ajmg.b.32380

Linkenkaer-Hansen, K., Smit, D. J., Barkil, A., van Beijsterveldt, T. E., Brussaard, A. B., Boomsma, D. I., et al. (2007). Genetic contributions to long-range temporal correlations in ongoing oscillations. J. Neurosci. 27, 13882-13889. doi: 10.1523/JNEUROSCI.3083-07.2007

Liu, R., Dang, W., Du, Y., Zhou, Q., Liu, Z., and Jiao, K. (2015). Correlation of functional GRIN2A gene promoter polymorphisms with schizophrenia and serum d-serine levels. Gene 568, 25-30. doi: 10.1016/j.gene.2015.05.011

Mai, G., Minett, J. W., and Wang, W. S.-Y. (2016). Delta, theta, beta, and gamma brain oscillations index levels of auditory sentence processing. Neuroimage 133, 516-528. doi: 10.1016/j.neuroimage.2016.02.064

Mallas, E. J., Carletti, F., Chaddock, C. A., Woolley, J., Picchioni, M. M., Shergill, S. S., et al. (2016). Genome-wide discovered psychosis-risk gene ZNF804A impacts on white matter microstructure in health, schizophrenia and bipolar disorder. PeerJ 4:e1570. doi: 10.7717/peerj.1570

Manoach, D. S., Pan, J. Q., Purcell, S. M., and Stickgold, R. (2015). Reduced sleep spindles in schizophrenia: a treatable endophenotype that links risk genes to impaired cognition? Biol. Psychiatry. doi: 10.1016/j.biopsych.2015.10.003. [Epub ahead of print].
McCarthy, S. E., Gillis, J., Kramer, M., Lihm, J., Yoon, S., Berstein, Y., et al. (2014). De novo mutations in schizophrenia implicate chromatin remodeling and support a genetic overlap with autism and intellectual disability. Mol. Psychiatry 19, 652-658. doi: 10.1038/mp.2014.29

McKenna, P. J., and Oh, T. M. (2005). Schizophrenic Speech: Making Sense of Bathroots and Ponds that Fall in Doorways. Cambridge: Cambridge University Press.

Meyer, M., Kircher, M., Gansauge, M. T., Li, H., Racimo, F., Mallick, S., et al. (2012). A high-coverage genome sequence from an archaic Denisovan individual. Science 338, 222-226. doi: 10.1126/science.1224344

Mitchell, A. C., Jiang, Y., Peter, C., and Akbarian, S. (2015). Transcriptional regulation of GAD1 GABA synthesis gene in the prefrontal cortex of subjects with schizophrenia. Schizophr. Res. 167, 28-34. doi: 10.1016/j.schres.2014. 10.020

Molina, V., Papiol, S., Sanz, J., Rosa, A., Arias, B., Fatjó-Vilas, M., et al. (2011). Convergent evidence of the contribution of TP53 genetic variation (Pro72Arg) to metabolic activity and white matter volume in the frontal lobe in schizophrenia patients. Neuroimage 56, 45-51. doi: 10.1016/j.neuroimage.2011. 01.076

Mor, E., Kano, S., Colantuoni, C., Sawa, A., Navon, R., and Shomron, N. (2013). MicroRNA-382 expression is elevated in the olfactory neuroepithelium of schizophrenia patients. Neurobiol. Dis. 55, 1-10. doi: 10.1016/j.nbd.2013.03.011

Moran, L. V., and Hong, L. E. (2011). High versus low frequency neural oscillations in schizophrenia. Schizophr. Bull. 37, 659-663. doi: 10.1093/schbul/sbr056

Morice, R., and Ingram, J. C. L. (1982). Language analysis in schizophrenia. Aust. N.Z. J. Psychiatry 16, 11-21. doi: 10.3109/00048678209161186

Morice, R., and McNicol, D. (1985). The comprehension and production of complex syntax in schizophrenia. Cortex 21, 567-580. doi: 10.1016/S00109452(58)80005-2

Morice, R., and McNicol, D. (1986). Language changes in schizophrenia. Schizophr. Bull. 12, 239-250. doi: 10.1093/schbul/12.2.239

Murphy, E. (2015a). The brain dynamics of linguistic computation. Front. Psychol. 6:1515. doi: 10.3389/fpsyg.2015.01515

Murphy, E. (2015b). Labels, cognomes and cyclic computation: an ethological perspective. Front. Psychol. 6:715. doi: 10.3389/fpsyg.2015.00715

Murphy, E. (2016). The human oscillome and its explanatory potential. Biolinguistics 10, 6-20.

Nakamura, T., Matsumoto, J., Takamura, Y., Ishii, Y., Sasahara, M., Ono, T., et al. (2015). Relationships among parvalbumin-immunoreactive neuron density, phase-locked gamma oscillations, and autistic/schizophrenic symptoms in PDGFR- $\beta$ knock-out and control mice. PLoS ONE 10:e0119258. doi: 10.1371/journal.pone. 0119258

Narayan, S., Tang, B., Head, S. R., Gilmartin, T. J., Sutcliffe, J. G., Dean, B., et al. (2008). Molecular profiles of schizophrenia in the CNS at different stages of illness. Brain Res. 1239, 235-248. doi: 10.1016/j.brainres.2008.08.023

Narita, H. (2014). Endocentric Structuring of Projection-free Syntax. Amsterdam: John Benjamins.

Newbury, D. F., Paracchini, S., Scerri, T. S., Winchester, L., Addis, L., Richardson, A. J., et al. (2011). Investigation of dyslexia and SLI risk variants in readingand language-impaired subjects. Behav. Genet. 41, 90-104. doi: 10.1007/s10519010-9424-3

Nguyen, P. T., Nakamura, T., Hori, E., Urakawa, S., Uwano, T., Zhao, J., et al. (2011). Cognitive and socio-emotional deficits in platelet-derived growth factor receptor- $\beta$ gene knockout mice. PLOS ONE 6:e18004. doi: 10.1371/journal.pone.0018004

Ni, X., Trakalo, J., Valente, J., Azevedo, M. H., Pato, M. T., Pato, C. N., et al. (2005). Human p53 tumor suppressor gene (TP53) and schizophrenia: case-control and family studies. Neurosci. Lett. 388, 173-178. doi: 10.1016/j.neulet.2005.06.050

Nicodemus, K. K., Elvevåg, B., Foltz, P. W., Rosenstein, M., Diaz-Asper, C., and Weinberger, D. R. (2014). Category fluency, latent semantic analysis and schizophrenia: a candidate gene approach. Cortex 55, 182-191. doi: 10.1016/j.cortex.2013.12.004

Nunez, P. L., and Srinivasan, R. (2006). Electric Fields of the Brain: The Neurophysics of EEG. 2nd Edn. Oxford: Oxford University Press.

Nunez, P. L., Wingeier, B. M., and Silberstein, R. B. (2001). Spatial-temporal structures of human alpha rhythms: theory, microcurrent sources, multiscale 
measurements, and global binding of local networks. Hum. Brain Mapp. 13, 125-164. doi: 10.1002/hbm.1030

O'Tuathaigh, C. M., Desbonnet, L., Moran, P. M., and Waddington, J. L. (2012). Susceptibility genes for schizophrenia: mutant models, endophenotypes and psychobiology. Curr. Top. Behav. Neurosci. 12, 209-250. doi: 10.1007/7854_2011_194

Ogawa, L. M., and Vallender, E. J. (2014). Evolutionary conservation in genes underlying human psychiatric disorders. Front. Hum. Neurosci. 8:283. doi: 10.3389/fnhum.2014.00283

Ohi, K., Shimada, T., Nitta, Y., Kihara, H., Okubo, H., Uehara, T., et al. (2016). Specific gene expression patterns of 108 schizophrenia-associated loci in cortex. Schizophr. Res. 174, 35-38. doi: 10.1016/j.schres.2016.03.032

Onwuameze, O. E., Nam, K. W., Epping, E. A., Wassink, T. H., Ziebell, S., Andreasen, N. C., et al. (2013). MAPK14 and CNR1 gene variant interactions: effects on brain volume deficits in schizophrenia patients with marijuana misuse. Psychol. Med. 43, 619-631. doi: 10.1017/S0033291712001559

Oribe, N., Onitsuka, T., Hirano, S., Hirano, Y., Maekawa, T., Obayashi, C., et al. (2010). Differentiation between bipolar disorder and schizophrenia revealed by neural oscillation to speech sounds: an MEG study. Bipolar Disord. 12, 804-812. doi: 10.1111/j.1399-5618.2010.00876.x

Osbun, N., Li, J., O’Driscoll, M. C., Strominger, Z., Wakahiro, M., Rider, E., et al. (2011). Genetic and functional analyses identify DISC1 as a novel callosal agenesis candidate gene. Am. J. Med. Genet. A 155A, 1865-1876. doi: 10.1002/ajmg.a.34081

Pääbo, S. (2014). The human condition: a molecular approach. Cell 157, 216-226. doi: 10.1016/j.cell.2013.12.036

Pérez-Santiago, J., Diez-Alarcia, R., Callado, L. F., Zhang, J. X., Chana, G., White, C. H., et al. (2012). A combined analysis of microarray gene expression studies of the human prefrontal cortex identifies genes implicated in schizophrenia. J. Psychiatr. Res. 46, 1464-1474. doi: 10.1016/j.jpsychires.2012.08.005

Peter, B., Raskind, W. H., Matsushita, M., Lisowski, M., Vu, T., Berninger, V. W., et al. (2011). Replication of CNTNAP2 association with nonword repetition and support for FOXP2 association with timed reading and motor activities in a dyslexia family sample. J. Neurodev. Disord. 3, 39-49. doi: 10.1007/s11689-0109065-0

Petrin, A. L., Giacheti, C. M., Maximino, L. P., Abramides, D. V., Zanchetta, S., Rossi, N. F., et al. (2010). Identification of a microdeletion at the 7q33-q35 disrupting the CNTNAP2 gene in a Brazilian stuttering case. Am. J. Med. Genet. A 152A, 3164-3172. doi: 10.1002/ajmg.a.33749

Pittman-Polletta, B. R., Kocsis, B., Vijayan, S., Whittington, M. A., and Kopell, N. J. (2015). Brain rhythms connect impaired inhibition to altered cognition in schizophrenia. Biol. Psychiatry 77, 1020-1030. doi: 10.1016/j.biopsych.2015.02.005

Plum, F. (1972). Prospects for research on schizophrenia. 3. Neurophysiology. Neuropathological findings. Neurosci. Res. Program Bull. 10, 384-388.

Poelmans, G., Buitelaar, J. K., Pauls, D. L., and Franke, B. (2011). A theoretical molecular network for dyslexia: integrating available genetic findings. Mol. Psychiatry 16, 365-382. doi: 10.1038/mp.2010.105

Poeppel, D. (2012). The maps problem and the mapping problem: two challenges for a cognitive neuroscience of speech and language. Cogn. Neuropsychol. 29, 34-55. doi: 10.1080/02643294.2012.710600

Poot, M., van't Slot, R., Leupert, R., Beyer, V., Passarge, E., and Haaf, T. (2009). Three de novo losses and one insertion within a pericentric inversion of chromosome 6 in a patient with complete absence of expressive speech and reduced pain perception. Med. Genet. 52, 27-30. doi: 10.1016/j.ejmg.2008. 11.002

Popov, T., and Popova, P. (2015). Same clock, different time read-out: spontaneous brain oscillations and their relationship to deficient coding of cognitive content. NeuroImage 119, 316-324. doi: 10.1016/j.neuroimage.2015.06.071

Potkin, S. G., Macciardi, F., Guffanti, G., Fallon, J. H., Wang, Q., Turner, J. A., et al. (2010). Identifying gene regulatory networks in schizophrenia. Neuroimage 53, 839-847. doi: 10.1016/j.neuroimage.2010.06.036

Potkin, S. G., Turner, J. A., Guffanti, G., Lakatos, A., Fallon, J. H., Nguyen, D. D., et al. (2009). A genome-wide association study of schizophrenia using brain activation as a quantitative phenotype. Schizophr. Bull. 35, 96-108. doi: 10.1093/schbul/sbn155

Ramsden, P. (2013). Understanding Abnormal Psychology: Clinical and Biological Perspectives. London: SAGE Publications.
Rolstad, S., Pålsson, E., Ekman, C. J., Eriksson, E., Sellgren, C., and Landén, M. (2015). Polymorphisms of dopamine pathway genes NRG1 and LMX1A are associated with cognitive performance in bipolar disorder. Bipolar Disord. 17, 859-868. doi: 10.1111/bdi.12347

Roux, F., Wibral, M., Mohr, H. M., Singer, W., and Uhlhaas, P. J. (2012). Gammaband activity in human prefrontal cortex codes for the number of relevant items maintained in working memory. J. Neurosci. 32, 12411-12420. doi: 10.1523/JNEUROSCI.0421-12.2012

Schizophrenia Working Group of the Psychiatric Genomics Consortium (2014). Biological insights from 108 schizophrenia-associated genetic loci. Nature 511, 421-427. doi: 10.1038/nature13595

Schulman, J. J., Cancro, R., Lowe, S., Lu, F., Walton, K. D., and Llinás, R. R. (2011). Imaging of thalamocortical dysrhythmia in neuropsychiatry. Front. Hum. Neuroscience 5:69. doi: 10.3389/fnhum.2011.00069

Scott-Van Zeeland, A. A., Abrahams, B. S., Alvarez-Retuerto, A. I., Sonnenblick, L. I., Rudie, J. D., Ghahremani, D., et al. (2010). Altered functional connectivity in frontal lobe circuits is associated with variation in the autism risk gene CNTNAP2. Sci. Transl. Med. 2, 56-80. doi: 10.1126/scitranslmed.3001344

Sehested, L. T., Møller, R. S., Bache, I., Andersen, N. B., Ullmann, R., Tommerup, N., et al. (2010). Deletion of 7q34-q36.2 in two siblings with mental retardation, language delay, primary amenorrhea, and dysmorphic features. Am. J. Med. Genet. A 152A, 3115-3119. doi: 10.1002/ajmg.a.33476

Seshadri, S., Faust, T., Ishizuka, K., Delevich, K., Chung, Y., Kim, S. H., et al. (2015). Interneuronal DISC1 regulates NRG1-ErbB4 signalling and excitatoryinhibitory synapse formation in the mature cortex. Nat. Commun. 6:10118. doi: 10.1038/ncomms10118

Shifman, S., Johannesson, M., Bronstein, M., Chen, S. X., Collier, D. A., Craddock, N. J., et al. (2008). Genome-wide association identifies a common variant in the reelin gene that increases the risk of schizophrenia only in women. PLoS Genet. 4:e28. doi: 10.1371/journal.pgen.0040028

Shulha, H. P., Crisci, J. L., Reshetov, D., Tushir, J. S., Cheung, I., Bharadwaj, R., et al. (2012). Human-specific histone methylation signatures at transcription start sites in prefrontal neurons. PLoS Biol. 10:e1001427. doi: 10.1371/journal.pbio.1001427

Španiel, F., Horáček, J., Tintěra, J., and Ibrahim, I., Novák, T., Čermák, J., et al. (2011). Genetic variation in FOXP2 alters grey matter concentrations in schizophrenia patients. Neurosci. Lett. 493, 131-135. doi: 10.1016/j.neulet.2011.02.024

Spironelli, C., and Angrilli, A. (2015). Language-related gamma EEG frontal reduction is associated with positive symptoms in schizophrenia patients. Schizophr. Res. 165, 22-29. doi: 10.1016/j.schres.2015.04.003

Spironelli, C., Angrilli, A., Calogero, A., and Stegagno, L. (2011). Delta EEG band as a marker of left hypofrontality for language schizophrenia patients. Schizophr. Bull. 37, 757-767. doi: 10.1093/schbul/sbp145

Srinivasan, S., Bettella, F., Mattingsdal, M., Wang, Y., Witoelar, A., Schork, A. J., et al. (2016). Genetic markers of human evolution are enriched in schizophrenia. Biol. Psychiatry 80, 284-292. doi: 10.1016/j.biopsych.2015.10.009

Stephane, M., Kuskowski, M., and Gundel, J. (2014). Abnormal dynamics of language in schizophrenia. Psychiatry Res. 216, 320-324. doi: 10.1016/j.psychres.2014.02.027

Stephane, M., Pellizzer, G., Fletcher, C. R., and McClannahan, K. (2007). Empirical evaluation of language disorder in schizophrenia. J. Psychiatry Neurosci. 32, 250-258.

Suárez-Pinilla, P., Roiz-Santiañez, R., Ortiz-García de la Foz, V., Guest, P. C., Ayesa-Arriola, R., Córdova-Palomera, A., et al. (2015). Brain structural and clinical changes after first episode psychosis: focus on cannabinoid receptor 1 polymorphisms. Psychiatry Res. 233, 112-119. doi: 10.1016/j.pscychresns.2015.05.005

Sun, J., Tang, Y., Lim, K. O., Wang, J., Tong, S., Li, H., et al. (2014). Abnormal dynamics of EEG oscillations in schizophrenia patients on multiple time scales. IEEE Trans. Biomed. Eng. 61, 1756-1764. doi: 10.1109/TBME.2014.2306424

Takekita, Y., Fabbri, C., Kato, M., Nonen, S., Sakai, S., Sunada, N., et al. (2015). HTR1A gene polymorphisms and 5-HT1A receptor partial agonist antipsychotics efficacy in schizophrenia. J. Clin. Psychopharmacol. 35, 220-227. doi: 10.1097/JCP.0000000000000304

Tan, G. C., Doke, T. F., Ashburner, J., Wood, N. W., and Frackowiak, R. S. (2010). Normal variation in fronto-occipital circuitry and cerebellar structure with an 
autism-associated polymorphism of CNTNAP2. Neuroimage 53, 1030-1042. doi: 10.1016/j.neuroimage.2010.02.018

Tang, J., Chen, X., Xu, X., Wu, R., Zhao, J., Hu, Z., et al. (2006). Significant linkage and association between a functional (GT)n polymorphism in promoter of the N-methyl-d-aspartate receptor subunit gene (GRIN2A) and schizophrenia. Neurosci. Lett. 409, 80-82. doi: 10.1016/j.neulet.2006.09.022

Teffer, K., and Semendeferi, K. (2012). Human prefrontal cortex: evolution, development, and pathology. Prog. Brain Res. 195, 191-218. doi: 10.1016/B9780-444-53860-4.00009-X

Thomas, P., King, K., Fraser, W., and Kendall, R. E. (1987). Linguistic performance in schizophrenia: a comparison of patients with positive and negative symptoms. Acta Psychiatr. Scand. 76, 144-151. doi: 10.1111/j.16000447.1987.tb02877.x

Thygesen, J. H., Zambach, S. K., Ingason, A., Lundin, P., Hansen, T., Bertalan, M., et al. (2015). Linkage and whole genome sequencing identify a locus on 6q25-26 for formal thought disorder and implicate MEF2A regulation. Schizophr. Res. 169, 441-446. doi: 10.1016/j.schres.2015.08.037

Toro, R., Konyukh, M., Delorme, R., Leblond, C., Chaste, P., Fauchereau, F., et al. (2010). Key role for gene dosage and synaptic homeostasis in autism spectrum disorders. Trends Genet. 26, 363-372. doi: 10.1016/j.tig.2010.05.007

Tosato, S., Bellani, M., Bonetto, C., Ruggeri, M., Perlini, C., Lasalvia, A., et al. (2012). Is neuregulin 1 involved in determining cerebral volumes in schizophrenia? Preliminary results showing a decrease in superior temporal gyrus volume. Neuropsychobiology 65, 119-125. doi: 10.1159/000330584

Turner, S. J., Mayes, A. K., Verhoeven, A., Mandelstam, S. A., Morgan, A. T., and Scheffer, I. E. (2015). GRIN2A: an aptly named gene for speech dysfunction. Neurology 84, 586-593. doi: 10.1212/WNL.0000000000001228

Uhlhaas, P. J., Haenschel, C., Nikolic, D., and Singer, W. (2008). The role of oscillations and synchrony in cortical networks and their putative relevance for the pathophysiology of schizophrenia. Schizophr. Bull. 34, 927-943. doi: $10.1093 / \mathrm{schbul} / \mathrm{sbn} 062$

van Os, J., and Kapur, S. (2009). Schizophrenia. Lancet 374, 635-645. doi: 10.1016/S0140-6736(09)60995-8

Vawter, M. P., Usen, N., Thatcher, L., Ladenheim, B., Zhang, P., VanderPutten, D. M., et al. (2001). Characterization of human cleaved N-CAM and association with schizophrenia. Exp. Neurol. 172, 29-46. doi: 10.1006/exnr.2001.7790

Verbrugghe, P., Bouwer, S., Wiltshire, S., Carter, K., Chandler, D., Cooper, M., et al. (2012). Impact of the Reelin signaling cascade (ligands-receptors-adaptor complex) on cognition in schizophrenia. Am. J. Med. Genet B Neuropsychiatr. Genet. 159B, 392-404. doi: 10.1002/ajmg.b.32042

Vernes, S. C., Newbury, D. F., Abrahams, B. S., Winchester, L., Nicod, J., Groszer, M., et al. (2008). A functional genetic link between distinct developmental language disorders. N. Engl. J. Med. 359, 2337-2345. doi: 10.1056/NEJMoa 0802828

Vinogradov, S., and Herman, A. (2016). Psychiatric illnesses as oscillatory connectomopathies. Neuropsychopharmacology 41, 387-388. doi: 10.1038/npp. 2015.308

Walker, R. M., Hill, A. E., Newman, A. C., Hamilton, G., Torrance, H. S., Anderson, S. M., et al. (2012). The DISC1 promoter: characterization and regulation by FOXP2. Hum. Mol. Genet. 21, 2862-2872. doi: 10.1093/hmg/dds111

Waltereit, R., Leimer, U., von Bohlen und Halbach, O., Panke, J., Hölter, S. M., Garrett, L., et al. (2012). Srgap3 ${ }^{-/-}$mice present a neurodevelopmental disorder with schizophrenia-related intermediate phenotypes. FASEB J. 26, 4418-4428. doi: 10.1096/fj.11-202317

Wang, Y., Huang, Y., Peng, M., Cong, Z., Li, X., Lin, A., et al. (2015). Association between Silent Information Regulator 1 (SIRT1) gene polymorphisms and schizophrenia in a Chinese Han population. Psychiatry Res. 225, 744-745. doi: 10.1016/j.psychres.2014.11.027

Weiss, A. P., Dewitt, I., Goff, D., Ditman, T., and Heckers, S. (2005). Anterior and posterior hippocampal volumes in schizophrenia. Schizophr. Res. 73, 103-112. doi: 10.1016/j.schres.2004.05.018

Weisz, N., Wuhle, A., Monittola, G., Demarchi, G., Frey, J., Popov, T., et al. (2014). Prestimulus oscillatory power and connectivity patterns predispose conscious somatosensory perception. Proc. Natl. Acad. Sci. U.S.A. 111, E417-E425. doi: 10.1073/pnas.1317267111

Whalley, H. C., O'Connell, G., Sussmann, J. E., Peel, A., Stanfield, A. C., HayiouThomas, M. E., et al. (2011). Genetic variation in CNTNAP2 alters brain function during linguistic processing in healthy individuals. Am. J. Med. Genet. B Neuropsychiatr. Genet. 156B, 941-948. doi: 10.1002/ajmg.b.31241

Whitehouse, A. J., Bishop, D. V., Ang, Q. W., Pennell, C. E., and Fisher, S. E. (2011). CNTNAP2 variants affect early language development in the general population. Genes Brain Behav. 10, 451-456. doi: 10.1111/j.1601183X.2011.00684.X

Williams, S., and Boksa, P. (2010). Gamma oscillations and schizophrenia. J. Psychiatry Neurosci. 35, 75-77. doi: 10.1503/jpn.100021

Wilson, N. K., Lee, Y., Long, R., Hermetz, K., Rudd, M. K., Miller, R., et al. (2011). A novel microduplication in the neurodevelopmental gene SRGAP3 that segregates with psychotic illness in the family of a COS proband. Case Rep. Genet. 2011:585893. doi: 10.1155/2011/585893

Wockner, L. F., Noble, E. P., Lawford, B. R., Young, R. M., Morris, C. P., Whitehall, V. L., et al. (2014). Genome-wide DNA methylation analysis of human brain tissue from schizophrenia patients. Transl. Psychiatry 4, e339. doi: 10.1038/tp.2013.111

Worthey, E. A., Raca, G., Laffin, J. J., Wilk, B. M., Harris, J. M., Jakielski, K. J., et al. (2013). Whole-exome sequencing supports genetic heterogeneity in childhood apraxia of speech. J. Neurodev. Disord. 5:29. doi: 10.1186/1866-19 55-5-29

Xie, J., Gizatullin, R., Vukojevic, V., and Leopardi, R. (2015). The CCDC55 couples cannabinoid receptor CNR1 to a putative DISC1 schizophrenia pathway. Neuroscience 310, 723-730. doi: 10.1016/j.neuroscience.2015.10.012

Xu, T., Stephane, M., and Parhi, K. K. (2012). Selection of abnormal neural oscillation patterns associated with sentence-level language disorder in schizophrenia. Conf. Proc. IEEE Eng. Med. Biol. Soc. 2012, 4923-4926. doi: 10.1109/EMBC.2012.6347098

Xu, T., Stephane, M., and Parhi, K. K. (2013). Multidimensional analysis of the abnormal neural oscillations associated with lexical processing in schizophrenia. Clin. EEG Neurosci. 44, 135-143. doi: 10.1177/15500594124 65078

Yamada, K., Iwayama, Y., Hattori, E., Iwamoto, K., Toyota, T., Ohnishi, T., et al. (2011). Genome-wide association study of schizophrenia in Japanese population. PLoS ONE 6:e20468. doi: 10.1371/journal.pone.0020468

Yu, W., De Hert, M., Moons, T., Claes, S. J., Correll, C. U., and van Winkel, R. (2013). CNR1 gene and risk of the metabolic syndrome in patients with schizophrenia. J. Clin. Psychopharmacol. 33, 186-192. doi: 10.1097/JCP.0b013e318283925e

Yuan, A., Li, W., Yu, T., Zhang, C., Wang, D., Liu, D., et al. (2013). SOX10 rs139883 polymorphism is associated with the age of onset in schizophrenia. J. Mol. Neurosci. 50, 333-338. doi: 10.1007/s12031-013-9982-y

Zeledón, M., Eckart, N., Taub, M., Vernon, H., Szymanksi, M., Wang, R., et al. (2015). Identification and functional studies of regulatory variants responsible for the association of NRG3 with a delusion phenotype in schizophrenia. Mol. Neuropsychiatry 1, 36-46. doi: 10.1159/000371518

Zhang, B., Xu, Y. H., Wei, S. G., Zhang, H. B., Fu, D. K., Feng, Z. F., et al. (2014). Association study identifying a new susceptibility gene (AUTS2) for schizophrenia. Int. J. Mol. Sci. 15, 19406-19416. doi: 10.3390/ijms151119406

Zhang, J., Liao, G., Liu, C., Sun, L., Liu, Y., Wang, Y., et al. (2011). The association of CLOCK gene T3111C polymorphism and hPER3 gene 54-nucleotide repeat polymorphism with Chinese Han people schizophrenics. Mol. Biol Rep. 38, 349-354. doi: 10.1007/s11033-010-0114-2

Conflict of Interest Statement: The authors declare that the research was conducted in the absence of any commercial or financial relationships that could be construed as a potential conflict of interest.

The Review Editor PU and handling Editor AK declared their shared affiliation, and the handling Editor states that the process nevertheless met the standards of a fair and objective review.

Copyright (c) 2016 Murphy and Benitez-Burraco. This is an open-access article distributed under the terms of the Creative Commons Attribution License (CC BY). The use, distribution or reproduction in other forums is permitted, provided the original author(s) or licensor are credited and that the original publication in this journal is cited, in accordance with accepted academic practice. No use, distribution or reproduction is permitted which does not comply with these terms. 